\title{
Thylakoid grana stacking revealed by multiplex genome editing of LHCII encoding genes
}

Zeno Guardini ${ }^{1}$, Rodrigo L. Gomez ${ }^{1}$, Roberto Caferri ${ }^{1}$, Johannes Stuttmann ${ }^{2}$, Luca Dall'Osto ${ }^{1}$ and Roberto Bassi $^{1,{ }^{*}}$

${ }^{1}$ Dipartimento di Biotecnologie, Università di Verona, Strada Le Grazie 15, 37134, Verona, Italy

${ }^{2}$ Institute for Biology, Department of Plant Genetics, Martin Luther University Halle-Wittenberg, Weinbergweg 10, 06120 Halle (Saale), Germany

${ }^{*}$ Corrispondence: roberto.bassi@univr.it

keywords: chloroplast, thylakoids, grana, stroma membranes, stacking, LHC, LHCII, monomeric antennae, photosystem, photoprotection.

\section{Summary}

Land plant chloroplasts differ from algal ones for their thylakoid membranes being organized in grana: piles of vesicles paired by their stromal surface, forming domains including Photosystem (PS) II and its antenna while excluding PS I and ATPase to stroma membranes, connecting grana stacks. The molecular basis of grana stacking remain unclear. We obtained genotypes lacking the trimeric antenna complex (Lhcb1-2-3), the monomeric Lhcb4-5-6, or both. Full deletion caused loss of grana, while either monomers or trimers support $50 \%$ stacking. The expression of Lhcb5 alone restored stacking at 50\%, while Lhcb2 alone produced huge grana which broke down upon light exposure. Cyclic electron transport was maintained in the lack of stacking, while excitation energy balance between photosystems and the repair efficiency of damaged Photosystem II were affected. We conclude that grana evolved for need of regulating energy balance between photosystems under terrestrial canopy involving rapid changes in photon spectral distribution.

\section{Introduction}

The land plant cell chloroplast contains chlorophylls (Chl) and carotenoids (Car) within its inner membrane system called thylakoids, as recognized already by Meyer in 1883 (Gunning et al., 2006). Its most distinctive feature is the thylakoid organization into grana stacks (Wietrzynski et al., 2020), a feature of land plant species, with size dependent on growth light intensity (Heitz, 1936) and spectra (Iwai et al., 2018; Kyle et al., 1983), which is absent in algae (Vallon et al., 1991). Grana are stacks of round, flattened vesicles (Granick \& Porter, 1947) connected to each other by pairs of unstacked membranes, called stromal membranes, intersecting grana at an angle, suggesting a helical arrangement (Paolillo \& Reighard, 2011). Freeze-etching 
bioRxiv preprint doi: https://doi.org/10.1101/2021.12.31.474624; this version posted January 1,2022 . The copyright holder for this preprint (which was not certified by peer review) is the author/funder, who has granted bioRxiv a license to display the preprint in perpetuity. It is made available under aCC-BY-NC-ND 4.0 International license.

electron microscopy (EM) coupled to mutant analysis showed that the photosynthetic pigment-protein complexes of thylakoid membranes are compartimented: photosystem (PS) II particles in the appressed region of the grana (Armond \& Arntzen, 1977; Simpson \& Robinson, 1984); PSI and ATPase complexes hosted in stromal membranes (Armond et al., 1977; Simpson, 1982). Cytochrome (Cyt) $b_{6} f$ complex was enriched in stromal domains and grana margins (Allred \& Staehelin, 1985; Olive et al., 1986; Vallon et al., 1991). Biochemical and immunocytochemical analysis supported differential compartimentation of PSI and PSII (Anderson \& Melis, 1983; Vallon et al., 1991), arguably for preventing excitation energy spillover from PSII to PSI, owing to the low energy chlorophyll spectral forms of plant PSI-LHCI (Murata, 1969). Since photosynthetic electron transport occurs linearly between PSs, the Plastoquinone (PQ) diffusion towards Cyt $b_{6} f$ is restricted by PSII crowding in grana partitions (Lavergne \& Joliot, 1991) similar to the diffusion of plastocyanin (PC) in the narrow thylakoid lumen (Kirchhoff et al., 2011), thus limiting linear electron flow (LET) rate. Restriction of diffusion also applies to PSII damaged by photoinhibition, which need to reach the stromal domains in order to be repaired (Mattoo et al., 1989). Thus, the size of granal vs. stromal domains appear to compromise between the positive effect of ensuring adequate excitation energy to both PSs and the negative effect of restricting PQ diffusion and PSII repair rate. This is consistent with PQ overreduction activating STN-7 and -8 kinases, which phosphorylates, respectively, the Lhcb2 subunit trimeric antenna (LHCII) and PSII core, yielding into reduced granal diameter (Bassi et al., 1989; Hepworth et al., 2021). Thus, LHCII subunits, diffuse to PSI-LHCl. This boosts PSI photon cross section causing oxidation of plastoquinol $\left(\mathrm{PQH}_{2}\right)$ (Kyle et al., 1983) and kinase inactivation, balancing PSI vs. PSIl activity. It was proposed that the reduction of grana domains enhances the fraction of $C y t b_{6} f$ in stromal membranes and favors cyclic electron flow (CEF) and ATP synthesis, thus helping to meet the NADPH/ATP ratio required for $\mathrm{CO}_{2}$ fixation (Kramer \& Evans, 2011) and adding to the regulatory value of grana stacking dynamics. In this context it is important to clarify the mechanism of grana stacking. Reverse genetics and EM analysis yielded controversial results: intermittent light grown plants becomes LHCII-deficient and exhibit limited grana (Argyroudi-Akoyunoglou et al., 1971; Armond et al., 1976); however, chlorina $f 2$ mutants of barley lack Chl $b$ and are depleted in LHCs, yet they retained extensive grana stacks and photosystem lateral heterogeneity (Bassi et al., 1985; Kim et al., 2009). Grana stacks were also retained in the viridis115 barley mutants, lacking PSII core complex, and in the double mutant viridis $115 \times$ chlorina f2 (Simpson et al., 1989), suggesting that neither of the two major thylakoid components located in grana partitions (LHCII and PSII core) was essential for grana stacking. Chloroplasts lacking grana can be found in bundle sheath (BS) cells of maize leaves, with a reduced PSII activity and a low LHCII level (Bassi et al., 1995). Also, LHCII of BS exhibited a simpler polypeptide composition with respect to mesophyll chloroplasts (Bassi \& Simpson, 1986) suggesting that specific gene products within LHC, rather than any member of the family, might be responsible for stacking. Here, we proceeded to the reverse genetic analysis of grana stacking by a combination of genome editing (GE) and EM. Previous work showed that PSII core complex-less plants plants (Belgio et al., 2014; Campoli et al., 2009; Margulies, 1966) 
enhance stacking, we focused on LHCs: genotypes lacking either monomeric or trimeric LHC gene products or both were produced and analyzed for stacking by transmission EM. In addition, Lhcb2, a minor component trimeric LHCII, reported to be needed for state 1 - state 2 transitions (Pietrzykowska et al., 2014), was expressed as the only LHC component and found to induce the formation of extensive stacking in dark conditions, which were broken down upon light-induced phosphorylation. Our results show that a major thylakoid stacking is caused by minority components of the PSII antenna system, namely Lhcb5 (CP26) and Lhcb2, which respectively mediate the constitutive and dynamic components of thylakoid stacking, which is required for efficient of PSII repair and balance of excitation energy; instead, it does not significantly change the rate of linear vs. cyclic electron transport.

\section{Results}

\section{Construction of Arabidopsis genotypes with selectively reduced PSII antenna system by GE}

The construction of Arabidopsis thaliana genotypes affected in LHC protein composition was performed from either the knock-out (ko) line koLhcb3, missing the Lhcb3 component of the major LHCII complex, or the NoM koLhcb3 genotype, devoid of the Lhcb4-6 genes encoding monomeric LHCs: Lhcb4 (CP29), CP26 and Lhcb6 (CP24)(Dall'Osto et al., 2017), as well as Lhcb3 (Supplementary Figure S1-A). To obtain the Lhcb-free genotype, CRISPR-CAS9 targeted mutagenesis strategy was implemented according to (Ordon et al., 2020): for each of the 5 LHCB1 and 3 LHCB2 genes, pairs of sg (single guide) RNAs were designed within coding sequences (Supplementary Table S1), with the aim of producing large DNA deletions, favoring DNA repair by non-homologous end-joining (NHEJ) (Malzahn et al., 2017). Lhcb1 and Lhcb2 genes were separately targeted to get Lhcb1-less and Lhcb2-less plants, which were then crossed to obtain lines lacking both Lhcb1 and Lhcb2 proteins. Depending on whether this procedure was applied on koLhcb3 or NoM koLhcb3 genotype, we obtained either the koLHCII line (lacking all LHCII but retaining monomeric Lhcb4-6 proteins), or the koLhcb line, lacking both the monomeric and trimeric LHCs of PSII. In both cases LHCl proteins were unaffected. The low-LHCIl genotype was selected for the level of residual LHCII among the products of incomplete gene editing of both Lhcb1 and Lhcb2: the two selected lines contain one LHCII trimer per monomeric PSII core complex. NoM koLhcb1 koLhcb3 lines (Lhcb2-only) retained Lhcb2 as the unique PSII antenna (Supplementary Figure S1-B, Supplementary Table S2).

\section{Growth and pigment composition of LHC-depleted plants}

Plants of the different genotypes are shown in Figure 1A upon growth under light-limiting (LL) conditions $\left(150 \mu \mathrm{mol}\right.$ photons $\mathrm{m}^{-2} \mathrm{~s}^{-1}, 8 / 16 \mathrm{~h}$ photoperiod, $24^{\circ} \mathrm{C}$ ). Wild type showed the best growth. NoM and the two koLHCII lines accumulated between $45 \%$ and $50 \%$ with respect to the wild type; while the growth of koLhcb was far more reduced: the two independent lines grew less than $3 \%$ with respect to the wild type based on fresh weight (FW) (Figure 1B). The Chls content per leaf surface displayed a behavior similar to the growth 
bioRxiv preprint doi: https://doi.org/10.1101/2021.12.31.474624; this version posted January 1,2022 . The copyright holder for this preprint (which was not certified by peer review) is the author/funder, who has granted bioRxiv a license to display the preprint in perpetuity. It is made available under aCC-BY-NC-ND 4.0 International license.

pattern although changes were far smaller: NoM showed $25 \%$ less $\mathrm{Chl}$ vs. the wild type, while koLhcb lines about $50 \%$ Chls when compared to $\mathrm{koLHCll}$ and $25 \%$ with respect to the wild type, suggesting that the growth rate per pigment unit was higher in the presence of monomeric antenna proteins (Figure 1C). The pigment composition of the different genotypes reflected the abundance of the pigment-protein complexes residual from gene deletions. Thus, $\mathrm{Chl} a / b$ ratio was the lowest in NoM (3.28 vs 3.51 in the wild type), the highest in koLhcb (6.21) and intermediate in KoLHCII (5.19), consistent with the lower Chl $b$ content of monomeric Lhcbs vs LHCII (Table I). LHCl complexes, unaffected in our genotypes, account for the residual $\mathrm{Chl} b$ content in koLhcb. The Chl/Car ratio ranged from 3.0 to 3.7 slightly decreasing with LHC content (Table I). The higher Car /Chl ratio in KoLHC lines resulted from increased $\beta$-carotene accumulation, which doubled in koLhcb with respect to the LHCII-rich wild type and NoM (Supplementary Table S3). Neoxanthin decreased by $60 \%$ and $80 \%$, respectively in $k o L H C I l$ and $k o L h c b$, with a concomitant increase in violaxanthin content owing to the preferential location of neoxanthin in trimeric LHCII and its absence in PSI-LHCl complexes (Schiphorst \& Bassi, 2020).

The major differences in growth between mutants might be due to either the large differences in PSII antenna size, thus limiting the photon harvesting, and/or to defects in the electron transport chain induced by changes in the organization of the thylakoid membranes. We thus proceeded to grow plants at higher irradiance, expected to compensate for antenna size limitation, yet avoiding excess irradiation in order to circumvent photodamage. Figure 1D shows wild type and LHC mutant genotypes grown at moderately high light (HL, 350 $\mu \mathrm{mol}$ photons $\mathrm{m}^{-2} \mathrm{~s}^{-1}, 8 / 16 \mathrm{~h}$ photoperiod, $24^{\circ} \mathrm{C}$ ). NoM and koLHCII grew similarly while koLhcb was far slower and grew as in control light light (150 $\mu \mathrm{mol}$ photons $\left.\mathrm{m}^{-2} \mathrm{~s}^{-1}\right)$ (Figure 1B, D). Thus, enhancing irradiance did not complement for the decreased growth phenotype evidenced under LL conditions and, in some cases, made it even stronger. This suggests that insufficient photon harvesting was unlikely the major cause of the differences in growth between genotypes. On the other hand, none of the lines were obviously photodamaged, or died at $350 \mu \mathrm{mol}$ photons $\mathrm{m}^{-2} \mathrm{~s}^{-1}$, suggesting that photoprotection was stronghly reduced.

\section{Pigment-protein complexes and photosynthetic function in antenna mutants}

The actual pigment-protein content of the genotypes as well as their supramolecular organization was investigated by non-denaturing Deriphat-PAGE upon solubilization with low $(0,8 \%) \alpha$-DM. Consistent with previous reports (Dall'Osto et al., 2014, 2017), the NoM genotype was depleted in PSII supercomplexes and over-accumulated the major trimeric antenna LHCII (Figure 2A). The trimeric LHCII band was completely absent in both koLHCII and koLhcb genotypes. These were also depleted of high molecular weight (MW) supercomplexes except for two bands migrating just above PSI-LHCI (BD1 and BD2). A faint green band (BD3) was detected migrating slightly below trimeric LHCII in both $k o L H C I I$ and $k o L h c b$, while a fourth band (BD4) was detected in both $\mathrm{koLHCll}$ and $k o L h c b$, migrating as the monomeric Lhcbs (Figure 2A). Biochemical and spectroscopical analyses revealed BD1 and BD2 being composed of PSI-LHCl complexes with different LHC 
bioRxiv preprint doi: https://doi.org/10.1101/2021.12 31.474624; this version posted January 1, 2022. The copyright holder for this preprint (which was not certified by peer review) is the author/funder, who has granted bioRxiv a license to display the preprint in perpetuity. It is made available under aCC-BY-NC-ND 4.0 International license.

133 complements, BD3 contained dimeric LHCl subunits, BD4 comprised monomeric Lhcbs in koLHCll and monomeric $\mathrm{LHCl}$ in koLhcb (Supplementary Figure S2).

135

The functional antenna size of PSII was determined from the rise time of Chl fluorescence in DCMU-treated leaves. Compared to the wild type, NoM had nearly twice the capacity for PSII photon harvesting, while koLHCII and koLhcb antenna size, scored $30 \%$ and $45 \%$ respectively, vs. the wild type (Figure $2 \mathrm{~B}$ ). When PSII activity was probed without DCMU in order to determine the maximum quantum yield of photochemistry, the wild type and koLHCIl scored very high, i.e. 0.82 and 0.76 respectively. Instead, NoM and koLhcb showed a low quantum yield, corresponding to 0.62 and 0.51 respectively (Figure $2 \mathrm{C}$ ).

\section{Thylakoid membranes organization}

Antenna proteins of PSII are the most abundant components of thylakoid membranes, suggesting that thylakoid organization could be affected in LHC-less genotypes. Indeed, the trimeric LHCII complex has been suggested to be the major determinant of grana stacking (Standfuss et al., 2005) and of the consequent domain segregation of the thylakoids, which is typical of land plant chloroplasts and is the basis for multiple regulation and biogenetic mechanisms essential for photosynthesis in the challenging terrestrial environment, such as PSII repair cycle and state 1 - state 2 transitions. To verify the effect of LHCII abundance in the different genotypes, we have analyzed the extent of grana stacks by transmission EM (Figure 3A-G). All genotypes had chloroplasts with the same size in ultrathin sections (Figure $3 \mathrm{H}$ ). Grana stacks were defined as made of at least three thylakoid appressions; the stacks diameter was approx. $450 \mathrm{~nm}$ and was found to be very similar between genotypes, only NoM showed a slightly larger grana diameter of approximately 550 $\mathrm{nm}$ (Figure 31). However, see below for the special case of the Lhcb2-only genotype.

Quantification of grana stack was performed by measuring the surface of grana stack vs. chloroplast area, since the total length of thylakoid membranes was th same across genotypes, (Figure 3K). Wild type chloroplasts had about $18 \%$ of their section area occupied by grana, a value that was reduced to $11 \%$ in KoLHCII and NoM. Deletion of LHCII in koLhcb caused a virtual absence of grana stacks $(<1 \%$ of stacked area, Figure $3 \mathrm{~K}$ ), while partial depletion of $\mathrm{LHCll}$ in the lowLHCII genotype yielded only a very partial recovery on surface occupied by grana to $3 \%$. We notice that $k$ oLHCIl retains more than $50 \%$ of its stacking ability, similar to NoM (Figure 3K), even though these two genotypes display highly diverse content in LHCs: koLHCII has three monomeric LHCS per PSII core, while NoM has about 6 LHCII trimers per PSII core, i.e. 60\% more LHCII with respect to the wild type (Dall'Osto et al., 2017). When comparing the stacking efficiency for a single LHC monomeric unit, the score is 6 times higher than when comparing the wild type to NoM, 3 times higher than comparing koLHCII to lowLHCII, the latters having the same LHC/PSIl core stoichiometry. This suggests that, although both monomeric and trimeric LHCs contributed to stacking, the monomeric LHCs were most critical 
bioRxiv preprint doi: https://doi.org/10.1101/2021.12.31.474624; this version posted January 1, 2022. The copyright holder for this preprint (which was not certified by peer review) is the author/funder, who has granted bioRxiv a license to display the preprint in perpetuity. It is made available under aCC-BY-NC-ND 4.0 International license.

determinants for grana formation. In all cases the number of events analyzed was statistically significant except for the case of $k o L h c b$, because most of the chloroplasts did not contain any stacks (Figure 3J).

Possibly, one of the clearest effects on grana stacking in previous research was obtained by controlling the expression of CURT genes (Heinz et al., 2016). Supplementary Figure S3 shows that no major differences were observed in the abundance of CURT, suggesting LHCII abundance/composition controlled stacking independently form CURT, or LHCII was needed for CURT activity.

To identify whether a specific subunit, among monomeric LHCs, had a special role in stacking, we analyzed the $c h 1$ genotype devoid of CAO ( $\mathrm{Chl} a$ oxygenase), which is known for a strongly reduced antenna size (Kim et al., 2009) caused by Lhcb proteins being destabilized in lack of Chl $b$. CP26, however, is particularly promiscuous for $\mathrm{Chl} a$ vs. $\mathrm{Chl} b$ binding (Croce et al., 2002) and is retained and functional in ch1 genotype (Havaux et al., 2007). We have analyzed by EM the extent of grana stacking in ch1 and ch1 koLhcb5 mutants (Figure 3F-G). First, we assessed that the chloroplast area and the diameter of grana in sections were very similar in ch1 and ch1 koLhcb5 genotypes with respect to the wild type and koLHCII (Figure 3H,I). ch1 had similar stacking as the KoLHCII genotypes (Figure 3K), suggesting that whatever induced stacking in $\mathrm{koLHCII}$ was still present in ch1. Instead, stacking was drastically reduced in the ch1 koLhcb5 genotype (Figure 3G,K), implying that CP26, among monomeric LHCs, had a prominent function on grana formation.

\section{Lhcb2 controls changes in grana stacking during State 1 - State 2 transitions}

Arabidopsis lines depleted on Lhcb2 proteins lacked state 1 - state 2 transitions (Pietrzykowska et al., 2014). The GE of Lhcb1 in the NoM koLhcb3 background (Supplementary Figure S1) produced a genotype retaining Lhcb2 as the only PSII antenna (Ordon et al., 2020). Wild type and mutant genotypes analyzed above showed grana diameters between 400 and $550 \mathrm{~nm}$ (Figure 3I), (Kirchhoff, 2019). The Lhcb2-only plants were striking different with respect to the lowLHCII lines: Despite having a similar PSII-core/LHCII ratio (Supplementary Figure S1), they also showed a few, yet much larger, grana with a diameter up to $3 \mu \mathrm{m}$ or even more (Figure $4 A-C)$, spanning the chloroplast sections, besides those alike observed wild type. We then proceeded to verify whether light exposure did affect thylakoid stacking. Dark-adapted leaves were illuminated with PSII light ( $200 \mu \mathrm{mol}$ photons $\mathrm{m}^{-2} \mathrm{~s}^{-1}, 24^{\circ} \mathrm{C}, 60 \mathrm{~min}$ ) in order to promote PQ over-reduction despite the small PSII antenna size of both Lhcb2-only and lowLHCII genotypes, thus Lhcb2 phosphorylation (Figure 4D). The very in Lhcb2-only chloroplasts large grana essentially broke down upon illumination, and the size distribution extended towards narrower diameters. In both Lhcb2-only and lowLHCII lines, grana length and level of stacking were significantly reduced by state 2 induction (Figure 4E-F).

\section{Physiological consequences of thylakoid stacking for photosynthesis}

Chloroplasts of unicellular algae do not show well-defined grana stacks, while cyanobacteria exhibit single membranes, showing that oxygenic photosynthesis can proceed without the need of a stacked organization 
bioRxiv preprint doi: https://doi.org/10.1101/2021.12.31.474624; this version posted January 1,2022 . The copyright holder for this preprint (which was not certified by peer review) is the author/funder, who has granted bioRxiv a license to display the preprint in perpetuity. It is made available under aCC-BY-NC-ND 4.0 International license.

of thylakoids (Mullineaux, 2005). Nevertheless, consequences of decreased level of stacking are clear from Figures 1 and 3: growth is dependent on the level of stacking, with the wild type showing both the maximal level of membrane stacking and the best growth. NoM and KoLHCIl exhibited intermediate level of both biomass yield and thylakoid stacking, while koLhcb has no grana and was severely impaired in growth. While these data clearly showed that growth rate and grana stacking were related, the functional reason(s) for the growth phenotype are still unclear. Grana stacking has been suggested to affect (1) light-harvesting, (2) the switch between CEF and LEF and/or (3) the repair of damaged PSII (Hepworth et al., 2021; Koochak et al., 2019; Mullineaux \& Emlyn-Jones, 2005; Pribil et al., 2014). We proceeded to evaluate whether the PSII repair rate was affected by thylakoid stacking. To this aim, leaves were treated with excess light to induce photoinhibition, as detected by $F_{v} / F_{m}$ ratio, which was reduced to about $30 \%$ of initial values in all genotypes. The recovery of $F_{v} / F_{m}$ was then followed under low light conditions $\left(15 \mu \mathrm{mol}\right.$ photons $\left.\mathrm{m}^{-2} \mathrm{~s}^{-1}, 24^{\circ} \mathrm{C}\right)$ favoring the PSII repair process (Mattoo et al., 1999). The results are shown in Figure 5A. Clearly, the wild type and koLHCII genotypes showed the same rate of PSII recovery. A similar dataset was published previously for the NoM genotype (Dall'Osto et al., 2020), showing no difference in the kinetic of recovery with respect to wild type plants. Instead, koLhcb healed its PSII activity to a much lower extent, suggesting that lateral heterogeneity between fully functional PSII in grana and PSII under repair in stroma-exposed margins might be necessary for a fully functional PSII repair cycle.

We then proceeded to verify whether the different level of thylakoid stacking did affect regulation of LEF vs. CEF amplitudes, a crucial mechanism to balance the chloroplast energy budget. To this aim, the kinetic of P700 $/$ P700 ratio was monitored in dark-adapted leaves upon far red illumination, when PSII has a far lower turnover rate than PSI. The slow P700 oxidation reflects a high CEF/LEF ratio, because the C3 cycle is inactive in dark-adapted leaves (Joliot \& Joliot, 2005) and suggested the capacity to perform CEF in all genotypes. The procedure was repeated at different time intervals, up to 10 minutes upon exposure to actinic light, thus allowing for full rate LEF. When comparing the results from the wild type, NoM, koLHCII and koLhcb, it clearly appeared that the oxidation rate of P700 increased after sequential periods of priming with light, thus implying that LEF replaced CEF in all genotypes. However, koLHCII and koLhcb reached lower level of P700 $/$ P700 ratio than the wild type, and CEF-to-LEF transition occurred more slowly in koLhcb leaves, likely due to their reduced PSII antenna size (Figure 5B).

We then measured $\mathrm{Chl}$ fluorescence and the kinetic of electrochromic shift (ECS) on leaves, as a measure of electrons and protons transfer in the photosynthetic apparatus, respectively (Figure $5 \mathrm{C}$ ). The quantum yield of PSII photochemistry can be used to measure the electron released from PSII (LEF) in leaves under a different light. ECS kinetics can be used to estimate fluxes of protons through the thylakoids, upon steadystate actinic illumination (Cruz et al., 2005): $\mathrm{ECS}_{\mathrm{t}}$, the total amplitude of the ECS signal upon light-dark transition, measures the light-driven protonmotive force (pmf) across the membrane, while the ECS decay lifetime $\left(\mathrm{gH}^{+}\right)$assesses the conductivity of the thylakoid ATPase to proton efflux. Under steady-state 
bioRxiv preprint doi: https://doi.org/10.1101/2021.12.31.474624; this version posted January 1, 2022. The copyright holder for this preprint (which was not certified by peer review) is the author/funder, who has granted bioRxiv a license to display the preprint in perpetuity. It is made available under aCC-BY-NC-ND 4.0 International license.

233 photosynthetic electron transport, the pmf produced by LEF alone can be estimated by the $\mathrm{LEF}_{\mathrm{gH}}{ }^{+}$ratio, a 234 parameter termed pmfLEF (Avenson et al., 2005). It turned out that the slope of the linear relationship of pmfLEF vs. ECS $S_{t}$ was proportional to the stoichiometry of electron vs. proton transfer. Figure $5 \mathrm{C}$ shows that wild type and mutant plants produced approximately the same extent of pmf that can be accounted for by LEF only, thus suggesting a similar CEF amplitude in all genotypes. Finally, the function of grana stacks, as for light-harvesting, consists in avoiding spill-over of excitons harvested by PSII-LHCII towards PSI-LHCl, which would unbalance the electron transport chain. This is obtained by partitioning PSI-LHCI and PSII-LHCII into two different domains of thylakoids. In order to verify the occurrence of spill-over, we have favored a 77K fluorescence spectroscopy approach. To this aim, we have compared fluorescence emission spectra of thylakoid membranes before and after treatment with very low concentrations of $\alpha$-DM $(0,0055 \%)$, which disconnects PSI-LHCI complex from LHCII and/or PSII core complexes in stroma-exposed membranes without solubilization (Caffarri et al., 2014)(Bassi et al., 1985; Caffarri et al., 2014) (Figure 5A). Upon excitation of Chl $a$ at $440 \mathrm{~nm}$, the fluorescence-emission spectra of wild-type thylakoids showed three peaks at 686, 695-700 and $735 \mathrm{~nm}$, respectively from Lhcb antenna proteins, PSII core and PSI-LHCI complexes. Emission by PSII can be described with two components, peaking at $684.5 \mathrm{~nm}$ for PSII antenna and $692 \mathrm{~nm}$ for core complex (Supplementary Figure S4). Upon $\alpha$-DM addition, the $695 \mathrm{~nm}$ shoulder component in $440 \mathrm{~nm}(\mathrm{Chl} \mathrm{a}$ ) excited spectra was drastically reduced, with a concomitant increase of the $684 \mathrm{~nm}$ peak consistent with disruption of excitation energy transfer (EET) from LHCII to PSII and/or PSI. Analysis of spectra from koLhcb showed two peaks only, at 689 and $735 \mathrm{~nm}$, from PSII core and PSI-LHCI, respectively. Since the $689 \mathrm{~nm}$ peak is weak and is enhanced by $\alpha$-DM, it can be concluded that PSII core was spilling-over excitation energy to PSI-LHCl and that this EET was severed by $\alpha$ DM. The analysis of spectra from koLHCIl confirmed and extended the above conclusions: the untreated thylakoids showed a spectrum very similar to koLhcb. Since both components were enhanced (especially the $685 \mathrm{~nm}$ peak from LHCS) upon $\alpha$-DM treatment, we explained the result as the release of quenching by PSILHCI on PSII-LHC complexes by $\alpha$-DM. The case of NoM is similar to that of the wild type: besides the broad peak at $735 \mathrm{~nm}$, the major peak occurred at $700 \mathrm{~nm}$ with a shoulder at $682 \mathrm{~nm}$, a blue-shifted emission component previously ascribed to antennae badly connected to the core (Dall'Osto et al., 2014). Upon $\alpha$-DM, the $680 \mathrm{~nm}$ shoulder was strongly enhanced. This suggests that the $\alpha$-DM treatment further disconnected the EET from LHCII to PSII core although the effect appeared incomplete when compared with the wild type, as evidenced by the emission at $700 \mathrm{~nm}$ from $\mathrm{Chl} a$ binding core upon excitation at $440 \mathrm{~nm}$.

\section{Discussion}

Grana stacks are the most conspicuous feature of plant chloroplasts, which attracted the attention of Mayer since 1883, when they were first reported (Gunning et al., 2006). The reasons for this interest is that grana are found in land plant, but are absent in algal chloroplast which, despite the obviously common function of 
bioRxiv preprint doi: https://doi.org/10.1101/2021.12.31.474624; this version posted January 1, 2022. The copyright holder for this preprint (which was not certified by peer review) is the author/funder, who has granted bioRxiv a license to display the preprint in perpetuity. It is made available under aCC-BY-NC-ND 4.0 International license.

chloroplasts through the species, do not have this highly structured multiple membrane layers, but still have differentiation between stacked and unstacked membrane domains (Trissl \& Wilhelm, 1993).

The deletion of either the inner layer (monomeric), or the outer layer (trimeric) antenna complexes, or both, had a strong impact on growth rate which was maximal with depletion of monomeric antennas, while the deletion of trimeric LHCll, although causing a moderate decrease in growth, did not affect biomass accumulation as much as it could be predicted by the difference in antenna size (Figure $1 \mathrm{~A}, \mathrm{~B}$ ). This is particularly evident when comparing the NoM with the wild type: since NoM strongly over-accumulates LHCII, its PSII antenna size, as determined by fluorescence induction with DCMU, is actually higher than the wild type and yet its growth is decreased by $50 \%$ (Figure $2 \mathrm{~B}$ ). We conclude that monomeric LHCs have an essential function in the efficiency of excitation energy transfer from outer antenna to RC of PSII, consistent with the high $F_{0}$ values previously reported for this genotype (Dall'Osto et al., 2014). The higher-than-wild type PSII antenna size in NoM is at odd with its reduced growth, implying that factors other than ET to PSII $\mathrm{RC}$ are involved in growth retardation. The stronger loss of growth is observed in the absence of both the antenna types. Again, the loss of biomass is far higher than suggested by the apparent reduction antenna size, strengthening the above conclusion. Growth retardation does not appear to be due to enhanced photodamage, because increasing photon fluence by a factor of three (Figure 1B,D) did enhance the growth rate of all the genotypes except for the koLhcb plants, whose growth was independent on light intensity. It should be noted that the strongest gain in growth when comparing HL vs. LL was obtained in the koLHCII plants which retained monomeric LHCs (+80\%), suggesting that these complexes are related to such growth promoting factors. The decrease in antenna size of the different phenotypes was associated to an higher PSII/PSI ratio (Figure 2A), a partial compensation for the reduced antenna size of PSII. Indeed, an enhanced PSII vs. PSI content and a low $\mathrm{F}_{\mathrm{m}} / \mathrm{F}_{0}$ ratio has been observed in the alga Mantoniella squamata that lacks grana stacks and thylakoid lateral heterogeneity because of a simplified antenna system composed of a single LHCII like protein (Rhiel \& Mörschel, 1993), which is shared by PSI and PSII RCS, leading to spill-over of PSII excitation energy by PSI (Wilhelm et al., 1989).

Based on evidence from basic photosynthetic parameters and the lesson from comparative analysis of thylakoid lateral heterogeneity in Mantoniella, Pleurochloris, Chlorella and higher plants (Trissl \& Wilhelm, 1993), it could be hypothesized that by knocking out LHC genes we had both decreased the PSII antenna size and reduced the lateral heterogeneity between PSI and PSII, likely by causing de-stacking of thylakoid membranes.

Thylakoid stacking. Indeed, the analysis of thylakoid stacking confirmed that the growth rate correlated to the extent of thylakoid stacking (Figure 3K). The extent of membrane stacking was decreased by $30 \%$ in both 
bioRxiv preprint doi: https://doi.org/10.1101/2021.12.31.474624; this version posted January 1,2022 . The copyright holder for this preprint (which was not certified by peer review) is the author/funder, who has granted bioRxiv a license to display the preprint in perpetuity. It is made available under aCC-BY-NC-ND 4.0 International license.

301 NoM and koLHCII plants, implying that components of both monomeric and trimeric LHC proteins were 302 involved in stabilizing grana partitions. The deletion of both PSII antenna types has a tremendous effect, in that only agranal chloroplasts were detected. The relevance of monomeric vs trimeric LHCs in eliciting grana stacking can be assessed by comparing the lowLHCII genotype, containing mostly Lhcb1 with little Lhcb2 gene products, with the $\mathrm{koLHClI}$, retaining monomeric complexes. These genotypes had the same overall total LHC antenna level. Since the lowLHCII plants had approximatively $18 \%$ stacking as compared to the one retaining the three monomeric complexes ( $k o L H C l l)$, we conclude that the efficiency of monomeric antennas in causing stacking was 5-6 times higher with respect to trimeric LHCII. It had to be established whether the three inner antennae equally contributed to the stacking, or if this property was specific to one of them. To this aim, we took advantage of the early observation that the ch1 mutant, in which a lack of Chl $b$ de-stabilizes LHCs, retained a substantial level of stacking which closely matched the level found in KoLHCII (Figure 3K) (Bassi et al., 1985). Loss of Chl $b$ prevented accumulation of all LHC proteins, yet CP26 (Lhcb5) was retained (Havaux et al., 2004) because CP26 can binding Chl $a$ at most of its $\mathrm{Chl} b$ binding sites (Croce et al., 2002). When the ch1 koLhcb5 double mutant was analyzed for thylakoid stacking it showed, indeed, a sharp decrease (Figure 3J), implying that Lhcb5 was a major determinant of grana formation. Last, but not less impressive, was the stacking phenotype of Lhcb2-only plants. Lhcb2 is present at low levels in thylakoids as compared to Lhcb1 and yet it was shown to be essential for state 1 - state 2 transitions (Pietrzykowska et al., 2014). State 1 state 2 transitions cause thylakoid de-stacking upon phosphorylation-dependent migration of LHCII trimers, containing both Lhcb1 and Lhcb2, from grana to stroma membranes (Bassi et al., 1989)(Hepworth et al., 2021). The huge grana stacks, far wider than in the wild type, evidenced in Lhcb2-only genotype (Fig. 4B) imply that Lhcb2 is prominent in mediating membrane appression into grana partitions. This was confirmed by the effect of inducing Lhcb2 phosphorylation with PSII light treatment (Figure 4D). Lhcb2 phosphorylation dramatically reduced the number of grana as well as their size (Figure $4 B, C, E$ ). We suggest that the grana remaining upon light treatment are promoted by un-phosphorylated LHCII. In a recent study, the formation of dimeric PSII supercomplexes connected by their stromal side was studied as a proxy for thylakoid stacking, by cross-linking and proteomic analysis. Consistent with our finding, both the monomeric and the trimeric antenna were suggested to mediate the interaction between PSII supercomplexes (Albanese et al., 2020). Nevertheless, the identity of the key gene products identified in that study (i.e. Lhcb1 and Lhcb4) does not match our in vivo analysis. Although these LHCs might well contribute to stacking, the genetic evidence we show here suggests that the major player in determining stacking and its regulation through phosphorylation are, indeed, the Lhcb5 and the Lhcb2 components of the LHCII trimeric antenna. This difference in attribution might be ascribed to the use of the purified dimeric PSII supercomplex fraction which, although reminiscent of face-to-face stacking, it might represent a PSII population resistant to detergent treatment yet not fully representative of the general PSII organization in grana partitions. Indeed, the same research group has recently reported on alternative organization forms of the face-to-face dimeric complexes (Grinzato et al., 
bioRxiv preprint doi: https://doi.org/10.1101/2021.12.31.474624; this version posted January 1, 2022. The copyright holder for this preprint (which was not certified by peer review) is the author/funder, who has granted bioRxiv a license to display the preprint in perpetuity. It is made available under aCC-BY-NC-ND 4.0 International license.

2020) and a recent high resolution study has identified two distinct conformations of the PSII C2S2 complex one of which is consistent with grana stacking being stabilized by interactions between CP26 and a LHCII subunit (Caspy et al., 2021). Alternatively, the differences with respect to our reports might well be ascribed to the in vivo vs. in vitro analysis: accessibility of the cross-linkers to individual LHC complexes might not correspond to the strength of interactions they elicit as thylakoid stacking determinants (A. Crepin \& Caffarri, 2018).

Functional significance of the granal stacking. In C3 plants and most green algae, the two PSs are well separated, making the possibility of exciton spilling from PSII antenna in a granal partition to PSI antenna pigments in the stroma-lamellae, rather small (Kirchhoff et al., 2007). This structural arrangement has the advantage of increasing the concentration of PSII, which is kinetically slower, by packing it densely in grana partitions and increasing the cooperativity between PSII RC beyond the obvious level of 2 defined by the dimeric organization of supercomplexes (Lavergne \& Joliot, 1991; Lavergne \& Trissl, 1995)(Lavergne \& Trissl, 1995). The high PSII/PSI stoichiometry ratio and high $\mathrm{F}_{\mathrm{m}} / \mathrm{F}_{0}$ ratio are in agreement with such good excitonic separation, which require state 1 - state 2 transitions in order to balance the turnover-rate when light is not equally absorbed by the two PSs (Miller \& Lyon, 1985). Moreover, the requirement for the CBB cycle and other metabolic uses of ATP/NADPH from the light phase of photosynthesis, is variable. Indeed, changes in CET vs. LET rates have been proposed to depend on state transitions and their effect in modulating the ratio between grana and stroma membranes (Hepworth et al., 2021). Last but not least, PSII is found in its fully functional state in grana partitions, while its repair process upon photoinhibition occurs in stroma membranes, where the machinery for disassembly of PSII core complex is located.

Analysis of these physiological processes in dependence of the extent of grana stacking showed that the efficiency of PSII repair process, i.e. the kinetic of recovery from photoinhibition, was severely affected in koLhcb as compared to koLHCII (Figure 5A). This effect could be due to the lack of monomeric LHCs in the former genotype or to the lack of grana. We favor the second hypothesis because the NoM genotype, although lacking monomeric LHCs, like koLhcb, shows recovery kinetic from photoinhibition as in the wild type (Dall'Osto et al., 2020). Instead, we did not observe any major differences in CET vs. LET depending on the level of grana stacking, because all genotypes undergo CET to LET transition, although at a different rate (Figure 5B). We interpret the slower transition from CEF to LEF observed in koLhcb and, to a lower extent, in koLHCII, as caused by the strongly reduced antenna size of this genotype, limiting electron supply and reduction of $\mathrm{P} 700+^{+}$. A strong change in the CET/LET ratio should be reflected in the slope of the electrochromic shift signal vs. protonmotive force, which was not observed since all genotypes behave similarly in this respect (Figure $5 \mathrm{C}$ ).

Lastly, we consider the possibility of excitation energy being spilled over from PSII to PSI upon thylakoid destacking. According to previous work with systems showing high spill-over, i.e. the liken Parmelia sulcata 
bioRxiv preprint doi: https://doi.org/10.1101/2021.12.31.474624; this version posted January 1, 2022. The copyright holder for this preprint (which was not certified by peer review) is the author/funder, who has granted bioRxiv a license to display the preprint in perpetuity. It is made available under aCC-BY-NC-ND 4.0 International license.

370 (Slavov et al., 2013) and the primitive unicellular green alga Mantoniella squamata (Trissl \& Wilhelm, 1993), 371 a low $\mathrm{F}_{\mathrm{m}} / \mathrm{F}_{0}$ ratio associated to the high PSII/PSI stoichiometry is the best indication of ongoing spill-over, as assessed by fast fluorescence spectroscopy at 77K and DAS deconvolution (Slavov et al., 2013). We observed that koLhcb has a similarly low $\mathrm{F}_{\mathrm{m}} / \mathrm{F}_{0}$ and PSII/PSI ratio as in Mantoniella while genotypes retaining significant level of stacking were similar to the wild type, i.e had high $\mathrm{F}_{\mathrm{m}} / \mathrm{F}_{0}$ and PSII/PSI $\sim 1$ (Supplementary Table S4). Furthermore, by treating thylakoids with sub-solubilizing concentration of $\alpha$-DM, which uncouples ET between pigment-proteins in thylakoids (Bassi et al., 1989), we observe a strong up-rise of PSI fluorescence emission bands in the genotypes (NoM, kOLHCII and koLhcb) with a reduced level of stacking, while in the wild type the effect was very small, if any. The case of koLhcb is particularly clear, since these thylakoids only contain PSII core and PSI-LHCl complexes, without any PSII antenna (Figure 5A). It should be noted that the canonical method for assessing spill-over consists in showing an increase of P700 antenna size in DCMUtreated samples (Wilhelm et al., 1989). We have attempted this experiment with unconclusive results. Indeed, our mutants, parlicularly KoLHCB, have a reduced cross section for photon absorption due to the very nature of the mutations applied: a PSII core complex binds $35 \mathrm{Chl} \mathrm{a} \mathrm{(Müh} \mathrm{\&} \mathrm{Zouni,} \mathrm{2020)} \mathrm{a} \mathrm{figure} \mathrm{that} \mathrm{might}$ be at the limit of detection for optically detected measurement since PSI-LHCI complex binds at least 145 Chls plus several LHCII complexes (Schiphorst et al., 2021). In order to fully verify the hypothesis of spill-over occurring differentially in our grana endowed vs grana depleted genotypes, fast spectroscopy measurements need to be performed and will be the object of future studies. Yet the occurrence of this process in our granadepleted genotypes is strongly consistent with data, namely the high $\mathrm{F}_{\mathrm{m}} / \mathrm{F}_{0}$ ratio of Mantoniella squamata (Rhiel \& Mörschel, 1993) and other photosynthetic systems without well defined compatimentation between psi and PSII RC.

We conclude that thylakoid stacking is a characteristic of specific and lowly abundant Lhcb proteins, namely Lhcb5 (CP26) and, chiefly, Lhcb2. Indeed, while CP26 is conserved in algae, Lhcb2 cannot be traced back though the green lineage from land plants to green algae, which, in turn, do not show grana. As for the major physiological functions associated to the evolution of grana, it is a more efficient PSII repair process, possibly due to the compartmentalization of the fully functional PSII separately from the damaged complex under repair and the energy separation of PSI from PSII antenna. Indeed, the evolution of red forms upon land colonization has made the effect of spill-over far more deleterious for an equilibrated energy balance between PSs with respect to algae, whose PSI is depleted in red-forms and is, therefore, less efficient in draining excitation energy from connected antenna beds, according to Boltzmann's relation.

\section{Aknowledgements}

401 We thank Pierre Joliot, Francis-André Wollman and Benjamin Bailleul for discussions and suggestions, the 


\section{Author contributions}

406 R.B. and L.D. conceived the work and designed the experiments. R.B. performed E.M. analysis. Z.G. carried out the construction of mutants and performed their physiological characterization, together with L.D. and

R.C. R.L.G. analyzed fluorescence kinetics and biochemically characterized mutant lines. J.S. developed and provided the CRISPR-Cas9 plasmids system. All authors contributed to writing the manuscript, discussed the results and commented on the manuscript.

\section{Declaration of Interest}

413 The authors declare no competing interests.

\section{Materials and Methods}

Plant materials. Arabidopsis thaliana mutants ch1, ch1 koLhcb5, koLhcb3 and NoM were obtained as previously described (Dall'Osto et al., 2014; Damkjaer et al., 2009; Havaux et al., 2007). NoM koLhcb3 was obtained by crossing single mutants and selecting progeny by immunoblotting. koLHCII, Lhcb2-only, koLhcb and lowLHCII lines were obtained by GE as reported in (Ordon et al., 2017, 2020). Plants were transformed (Zhang et al., 2006) with Agrobacterium tumefaciens (strain GV3101). Seedlings were tested for resistance to applications of the antibiotic hygromycin $\left(25 \mathrm{mg} \mathrm{l}^{-1}\right)$. For each genotype, independent transformants ( $\mathrm{T} 1$ generation) were self-fertilized, and absences of proteins were confirmed in the T3 generation by immunotitration.

Growth conditions. Wild type and mutant genotypes were grown in soil, in a phytotron for 6 weeks at either 150 or $350 \mu \mathrm{mol}$ photons $\mathrm{m}^{-2} \mathrm{~s}^{-1}, 23^{\circ} \mathrm{C}, 70 \%$ relative humidity, $8 / 16 \mathrm{~h}$ of day/night. All biochemical and physiological analyses were performed on plants prior to the onset of flowering. The growth of plants was determined by measuring the rosette fresh weight at the end of the growth cycle.

Membrane isolation. Stacked thylakoid membranes were isolated as previously described (Casazza et al., 2001).

Pigment analysis. Pigments were extracted from leaf discs with $85 \%$ acetone buffered with $\mathrm{Na}_{2} \mathrm{CO}_{3}$, then separated and quantified by HPLC (Jasco Extrema LC-4000) as in (Gilmore \& Yamamoto, 1991).

Electrophoresis and immunoblotting. SDS-PAGE analysis of thylakoid proteins was performed using the TrisTricine buffer system (Schägger \& von Jagow, 1987). For immunotitration (Towbin et al., 1979), proteins were detected with alkaline phosphatase-conjugated antibody (Sigma-Aldrich A3687). Primary antibodies used were: $\alpha$-PsbB/CP47 (AS04 038), $\alpha$-Lhcb1 (AS01 004), $\alpha$-Lhcb2 (AS01 003), $\alpha$-P-Lhcb1 (AS13 2704), $\alpha$-P-Lhcb2 (AS13 2705) from Agrisera. Signal amplitude was quantified using the GelPro 3.2 software (Bio-Rad). Nondenaturing Deriphat-PAGE was performed as in (Guardini et al., 2020). SDS-PAGE analysis on complexes 
439 eluted from non-denaturing gel was performed using the Laemmli system as reported in (Aurélie Crepin et 440 al., 2020).

441 Spectroscopy. Absorption spectra were recorded at RT using a Jasco V-550 spectrophotometer. Leaf pigment 442 content was calculated from spectra of acetonic extracts (Croce et al., 2002). Absorption measurements on 443 complexes eluted from non-denaturing gel were performed in 5\% glycerol, $10 \mathrm{mM}$ HEPES pH 7.5, $\alpha$-DM $444 \quad 0.004 \% .77 \mathrm{~K}$ fluorescence emission spectra $\left(\lambda_{\text {exc }} 440 \mathrm{~nm}, \sim 0.2 \mu \mathrm{g} \mathrm{Chl} \mathrm{mL}{ }^{-1}\right.$ in $50 \%$ glycerol, $10 \mathrm{mM} \mathrm{HEPES}, \mathrm{pH}$ 445 7.5) were recorded using a Jobin-Yvon Fluoromax-3 spectrofluorometer (Dall'Osto et al., 2017).

446 Analysis of Chl fluorescence. Photosynthetic parameters (Baker, 2008) were measured on leaves at RT with a 447 PAM 101 fluorimeter (Heinz-Walz). Changes in the redox state of P700 and CEF to LEF transition were 448 measured as in (Dal Corso et al., 2008) with a DUAL-PAM-100 equipment (Walz, GmbH). Variable 449 fluorescence was measured in a home-built Chl fluorimeter, and induced by green light (Rappaport et al., 450 2007) $\left(10 \mu \mathrm{mol}\right.$ photons $\left.\mathrm{m}^{-2} \mathrm{~s}^{-1}\right)$ in dark adapted leaves, infiltrated with DCMU $50 \mu \mathrm{M}$. Steady state, light451 induced pmf was estimated from changes in absorbance associated with the ECS at $520 \mathrm{~nm}$ (Cruz et al., 2005; 452 Livingston et al., 2010), using a LED spectrophotometer (JTS10; Biologic Science Instruments).

453 Electron Microscopy and image analysis. Transmission electron microscopy on leaf fragments was conducted 454 using a FEI Tecnai T12 electron microscope operating at $100 \mathrm{kV}$ accelerating voltage. Leaf fragments were 455 fixed in $3 \%$ glutaraldehyde in $0.1 \mathrm{M}$ cacodylate buffer $\mathrm{pH}$ 6.9. Analyses on EM images were conducted with 456 ImageJ software (Schneider et al., 2012).

457 LHCIl phosphorylation induction. Leaves were dark adapted for 60 minutes prior to exposure to $200 \mu \mathrm{mol}$ 458 photons $\mathrm{m}^{-2} \mathrm{~s}^{-1} \mathrm{PSII}$ light (orange) for 60 minutes at $22^{\circ} \mathrm{C}$.

459 Statistics. Statistical analyses were performed in SigmaPlot using One-way analysis of variance (ANOVA), 460 means were separated with Tukey's post hoc test at a significant level of $P<0.05$ (see the figure legends for 461 details). Error bars represent the standard deviation.

462 Data availability. Sequence data from this article can be found in the Arabidopsis Genome Initiative or 463 GenBank/EMBL databases under accession numbers At1g29920 (Lhcb1.1), At1g29910 (Lhcb1.2), At1g29930 464 (Lhcb1.3), At2g34430 (Lhcb1.4), At2g34420 (Lhcb1.5), At2g05100 (Lhcb2.1), At2g05070 (Lhcb2.2), At3g27690 465 (Lhcb2.3), At5g54270 (Lhcb3), At5g01530 (Lhcb4.1), At3g08940 (Lhcb4.2), At4g10340 (Lhcb5), At1g44446 466 (cao). The KO lines used in the work were obtained from the NASC under the stock numbers N376476 467 (koLhcb4.1), N877954 (koLhcb4.2), N514869 (koLhcb5), N520342 (koLhcb3), N524295 (ch1). 


\section{References}

Albanese, P., Tamara, S., Saracco, G., Scheltema, R. A., \& Pagliano, C. (2020). How paired PSII-LHCII supercomplexes mediate the stacking of plant thylakoid membranes unveiled by structural massspectrometry. Nature Communications, 11(1). https://doi.org/10.1038/s41467-020-15184-1

Allred, D. R., \& Staehelin, L. A. (1985). Lateral distribution of the cytochrome b6/f and coupling factor ATPsynthetase complexes of chloroplast thylakoid membranes. Plant Physiol., 78, 199-202.

Anderson, J. M., \& Melis, A. (1983). Localization of different photosystems in seperate regions of chloroplast membranes. Proc.Natl.Acad.Sci.USA, 80, 745-749.

Argyroudi-Akoyunoglou, J. H., Feleki, Z., \& Akoyunoglou, G. (1971). Formation of two chlorophyll-protein complexes during greening of etiolated bean leaves. Biochemical and Biophysical Research Communications, 45(3), 606-614. https://doi.org/10.1016/0006-291X(71)90460-8

Armond, P. A., \& Arntzen, C. J. (1977). Localization and Characterization of Photosystem II in Grana and Stroma Lamellae. Plant Physiology, 59(3), 398-404. https://doi.org/10.1104/pp.59.3.398

Armond, P. A., Arntzen, C. J., Briantais, J. M., \& Vernotte, C. (1976). Differentiation of chloroplast lamellae. Light harvesting efficiency and grana development. Archives of Biochemistry and Biophysics, 175(1), 54-63. https://doi.org/10.1016/0003-9861(76)90484-7

Armond, P. A., Staehelin, L. A., \& Arntzen, C. J. (1977). Spatial relationship of photosysten I, photosystem II, and the light-harvesting complex in chloroplast membranes. J.Cell Biol., 73, 400-418.

Avenson, T. J., Cruz, J. A., Kanazawa, A., \& Kramer, D. M. (2005). Regulating the proton budget of higher plant photosynthesis. Proceedings of the National Academy of Sciences of the United States of America, 102(27), 9709-9713. https://doi.org/10.1073/pnas.0503952102

Baker, N. R. (2008). Chlorophyll Fluorescence: A Probe of Photosynthesis In Vivo. Annual Review of Plant Biology, 59(1), 89-113. https://doi.org/10.1146/annurev.arplant.59.032607.092759

Bassi, R., Ghiretti Magaldi, A., Tognon, G., Giacometti, G. M., \& Miller, K. R. (1989). Two-dimensional crystals of the photosystem II reaction center complex from higher plants. European Journal of Cell Biology, 50(1), 84-93. https://europepmc.org/article/med/2693092

Bassi, R., Marquardt, J., \& Lavergne, J. (1995). Biochemical and fuctional properties of photosystem II in agranal membranes from maize mesophyll and bundle sheath chloroplasts. Eur.J.Biochem., 233, 709719.

Bassi, R., \& Simpson, D. J. (1986). Differential expression of LHCII genes in mesophyll and bundle sheath cells of maize. Carlsberg Research Communications, 51(6), 363-370. https://doi.org/10.1007/BF02907312

Bassi, R, Hinz, U., \& Barbato, R. (1985). The role of the light harvesting complex and photosystem II in thylakoid stacking in the chlorina-f2 barley mutant. Carlsberg Res.Commun., 50_ , 347-367.

Belgio, E., Kapitonova, E., Chmeliov, J., Duffy, C. D. P., Ungerer, P., Valkunas, L., \& Ruban, A. V. (2014). 
Economic photoprotection in photosystem II that retains a complete light-harvesting system with slow energy traps. Nature Communications, 5, 1-8. https://doi.org/10.1038/ncomms5433

Caffarri, S., Tibiletti, T., Jennings, R., \& Santabarbara, S. (2014). A Comparison Between Plant Photosystem I and Photosystem II Architecture and Functioning. Current Protein \& Peptide Science, 15(4), 296-331. https://doi.org/10.2174/1389203715666140327102218

Campoli, C., Caffarri, S., Svensson, J. T., Bassi, R., Stanca, A. M., Cattivelli, L., \& Crosatti, C. (2009). Parallel pigment and transcriptomic analysis of four barley Albina and Xantha mutants reveals the complex network of the chloroplast-dependent metabolism. Plant Molecular Biology, 71(1-2), 173-191.

Casazza, A. P., Tarantino, D., \& Soave, C. (2001). Preparation and functional characterization of thylakoids from Arabidopsis thaliana. Photosynth.Res., 68(0166-8595 (Print)), 175-180. https://doi.org/10.1023/A:1011818021875

Caspy, I., Fadeeva, M., Mazor, Y., \& Nelson, N. (2021). Structure of Dunaliella Photosystem II reveals conformational flexibility of stacked and unstacked supercomplexes. https://doi.org/10.1101/2021.11.29.470333

Crepin, A., \& Caffarri, S. (2018). Functions and evolution of Lhcb isoforms composing LHCII, the major light harvesting complex of Photosystem II of green eukaryotic organisms. Current Protein \& Peptide Science, 19. https://doi.org/10.2174/1389203719666180222101534

Crepin, Aurélie, Kučerová, Z., Kosta, A., Durand, E., \& Caffarri, S. (2020). Isolation and characterization of a large photosystem I-light-harvesting complex II supercomplex with an additional Lhca1-a4 dimer in Arabidopsis. Plant Journal, 102(2), 398-409. https://doi.org/10.1111/tpj.14634

Croce, R., Canino, G., Ros, F., \& Bassi, R. (2002). Chromophore organization in the higher-plant photosystem II antenna protein CP26. Biochemistry, 41(23), 7334-7343. https://doi.org/10.1021/bi0257437

Cruz, J. A., Avenson, T. J., Kanazawa, A., Takizawa, K., Edwards, G. E., \& Kramer, D. M. (2005). Plasticity in light reactions of photosynthesis for energy production and photoprotection. Journal of Experimental Botany, 56(411), 395-406. https://doi.org/10.1093/jxb/eri022

Dal Corso, G., Pesaresi, P., Masiero, S., Aseeva, E., Schünemann, D., Finazzi, G., Joliot, P., Barbato, R., \& Leister, D. (2008). A Complex Containing PGRL1 and PGR5 Is Involved in the Switch between Linear and Cyclic Electron Flow in Arabidopsis. Cell, 132(2), 273-285. https://doi.org/10.1016/j.cell.2007.12.028

Dall'Osto, L., Cazzaniga, S., Bressan, M., Paleček, D., Židek, K., Niyogi, K. K., Fleming, G. R., Zigmantas, D., \& Bassi, R. (2017). Two mechanisms for dissipation of excess light in monomeric and trimeric lightharvesting complexes. Nature Plants, 3(April), 17033. https://doi.org/10.1038/nplants.2017.33

Dall'Osto, L., Cazzaniga, S., Zappone, D., \& Bassi, R. (2020). Monomeric light harvesting complexes enhance excitation energy transfer from LHCII to PSII and control their lateral spacing in thylakoids. Biochimica et Biophysica Acta - Bioenergetics, 1861(4), 0-1. https://doi.org/10.1016/j.bbabio.2019.06.007 
Dall'Osto, L., Ünlü, C., Cazzaniga, S., \& Van Amerongen, H. (2014). Disturbed excitation energy transfer in Arabidopsis thaliana mutants lacking minor antenna complexes of photosystem II. BBA Bioenergetics, 1837(12), 1981-1988. https://doi.org/10.1016/j.bbabio.2014.09.011

Damkjaer, J., Kereiche, S., Johnson, M. P., Kovacs, L., a.z Kiss, Boekema, E. J., Ruban, A. V, Horton, P., \& Jansson, S. (2009). The Photosystem II light-harvesting protein Lhcb3 affects the macrostructure of Photosystem II and the rate of state transitions in Arabidopsis. Plant Cell, 21, 3245-3256.

Gilmore, A. M., \& Yamamoto, H. Y. (1991). Zeaxanthin Formation and Energy-Dependent Fluorescence Quenching in Pea Chloroplasts under Artificially Mediated Linear and Cyclic Electron Transport1. Plant Physiology, 96(2), 635-643. https://doi.org/10.1104/pp.96.2.635

Granick, S., \& Porter, K. R. (1947). THE STRUCTURE OF THE SPINACH CHLOROPLAST AS INTERPRETED WITH THE ELECTRON MICROSCOPE. American Journal of Botany, 34(10), 545-550. https://doi.org/10.1002/J.1537-2197.1947.TB13028.X

Grinzato, A., Albanese, P., Marotta, R., Swuec, P., Saracco, G., Bolognesi, M., Zanotti, G., \& Pagliano, C. (2020). High-Light versus Low-Light: Effects on Paired Photosystem II Supercomplex Structural Rearrangement in Pea Plants. International Journal of Molecular Sciences, 21(22), 8643. https://doi.org/10.3390/ijms21228643

Guardini, Z., Bressan, M., Caferri, R., Bassi, R., \& Dall'Osto, L. (2020). Identification of a pigment cluster catalysing fast photoprotective quenching response in CP29. Nature Plants, 6(3), 303-313. https://doi.org/10.1038/s41477-020-0612-8

Gunning, B., Koenig, F., \& Govindjee. (2006). A Dedication to Pioneers of Research on Chloroplast Structure. In R. R. Wise \& J. K. Hoober (Eds.), The structure and function of plastids (1st ed., pp. xxiii-xxxi). Springer.

Havaux, M., Dall'Osto, L., \& Bassi, R. (2007). Zeaxanthin has enhanced antioxidant capacity with respect to all other xanthophylls in Arabidopsis leaves and functions independent of binding to PSII antennae. Plant Physiol, 145(0032-0889 (Print)), 1506-1520.

Havaux, M., Dall'Osto, L., Cuiné, S., Giuliano, G., \& Bassi, R. (2004). The Effect of Zeaxanthin As the only Xanthophyll on the Structure and Function of the Photosynthetic Apparatus in Arabidopsis thaliana. Journal of Biological Chemistry, 279(14), 13878-13888. https://doi.org/10.1074/jbc.M311154200 Heinz, S., Rast, A., Shao, L., Gutu, A., Gügel, I. L., Heyno, E., Labs, M., Rengstl, B., Viola, S., Nowaczyk, M. M., Leister, D., \& Nickelsen, J. (2016). Thylakoid membrane architecture in Synechocystis depends on CurT, a homolog of the granal CURVATURE THYLAKOID1 proteins. Plant Cell, 28(9), 2238-2260. https://doi.org/10.1105/tpc.16.00491

Heitz, E. (1936). Untersuchungen Über den Bau der Plastiden. Planta 1936 26:1, 26(1), 134-163. https://doi.org/10.1007/BF01913844

Hepworth, C., Wood, W. H. J., Emrich-Mills, T. Z., Proctor, M. S., Casson, S., \& Johnson, M. P. (2021). 
Dynamic thylakoid stacking and state transitions work synergistically to avoid acceptor-side limitation of photosystem I. Nature Plants, 7(1), 87-98. https://doi.org/10.1038/s41477-020-00828-3

Iwai, M., Roth, M. S., \& Niyogi, K. K. (2018). Subdiffraction-resolution live-cell imaging for visualizing thylakoid membranes. Plant Journal, 96(1), 233-243. https://doi.org/10.1111/tpj.14021

Joliot, P., \& Joliot, A. (2005). Quantification of cyclic and linear flows in plants. Proc.Natl.Acad.Sci.U.S.A, 102(0027-8424 (Print)), 4913-4918.

Kim, E. H., Li, X. P., Razeghifard, R., Anderson, J. M., Niyogi, K. K., Pogson, B. J., \& Chow, W. S. (2009). The multiple roles of light-harvesting chlorophyll a/b-protein complexes define structure and optimize function of Arabidopsis chloroplasts: A study using two chlorophyll b-less mutants. Biochimica et Biophysica Acta - Bioenergetics, 1787(8), 973-984. https://doi.org/10.1016/j.bbabio.2009.04.009

Kirchhoff, H. (2019). Chloroplast ultrastructure in plants. New Phytologist, 223(2), 565-574. https://doi.org/10.1111/NPH.15730

Kirchhoff, H., Haase, W., Haferkamp, S., Schott, T., Borinski, M., Kubitscheck, U., \& Rögner, M. (2007). Structural and functional self-organization of Photosystem II in grana thylakoids. Biochimica et Biophysica Acta (BBA) - Bioenergetics, 1767(9), 1180-1188. https://doi.org/10.1016/J.BBABIO.2007.05.009

Kirchhoff, H., Hall, C., Wood, M., Herbstová, M., Tsabari, O., Nevo, R., Charuvi, D., Shimoni, E., \& Reich, Z. (2011). Dynamic control of protein diffusion within the granal thylakoid lumen. Proceedings of the

Kramer, D. M., \& Evans, J. R. (2011). The importance of energy balance in improving photosynthetic productivity. Plant Physiology, 155(1), 70-78. https://doi.org/10.1104/pp.110.166652

Kyle, D. J., Staehelin, L. A., \& Arntzen, C. J. (1983). Lateral mobility of the light-harvesting complex in chloroplast membranes controls excitation energy distribution in higher plants. Arch.Biochem.Biophys., 222, 527-541.

Lavergne, J., \& Joliot, P. (1991). Restricted Diffusion in Photosynthetic Membranes. Trends Biochem.Sci., 16, 129-134.

Lavergne, J., \& Trissl, H. W. (1995). Theory of fluorescence induction in photosystem II: derivation of analytical expressions in a model including exciton-radical-pair equilibrium and restricted energy transfer between photosynthetic units. Biophysical Journal, 68(6), 2474-2492. https://doi.org/10.1016/S0006-3495(95)80429-7 
high cyclic electron flow around photosystem i (hcef) involving the nadphdehydrogenase complex. Plant Cell, 22(1), 221-233. https://doi.org/10.1105/tpc.109.071084

Malzahn, A., Lowder, L., \& Qi, Y. (2017). Plant genome editing with TALEN and CRISPR. Cell and Bioscience, 7(1), 1-18. https://doi.org/10.1186/s13578-017-0148-4

Margulies, M. M. (1966). Effect of Chloramphenicol on Formation of Chloroplast Structure and Protein During Greening of Etiolated Leaves of Phaseolus vulgaris. Plant Physiology, 41(6), 992-1003. https://doi.org/10.1104/pp.41.6.992

Mattoo, A. K., Giardi, M.-T., Raskind, A., \& Edelman, M. (1999). Dynamic metabolism of photosystem II reaction center proteins and pigments. Physiologia Plantarum, 107(4), 454-461. https://doi.org/10.1034/J.1399-3054.1999.100412.X

Mattoo, A., K., Marder, J. B., \& Edelman, M. (1989). Dynamics of the photosystem II reaction center. Cell, $56,241-246$.

Miller, K. R., \& Lyon, M. K. (1985). Do we really know why chloroplast membranes stack? Trends in Biochemical Sciences, 10(6), 219-222. https://doi.org/10.1016/0968-0004(85)90132-X

Müh, F., \& Zouni, A. (2020). Structural basis of light-harvesting in the photosystem II core complex. Protein Science, 29(5), 1090-1119. https://doi.org/10.1002/pro.3841

Mullineaux, C. W. (2005). Function and evolution of grana. Trends in Plant Science, 10(11), 521-525. https://doi.org/10.1016/j.tplants.2005.09.001

Mullineaux, C. W., \& Emlyn-Jones, D. (2005). State transitions: An example of acclimation to low-light stress. Journal of Experimental Botany, 56(411), 389-393. https://doi.org/10.1093/jxb/eri064

Murata, N. (1969). Control of excitation transfer in photosynthesis. I. Light- induced change of chlorophyll a fluorescence in Porphyridium cruentum. Biochim.Biophys.Acta, 172, 242-251.

Olive, J., Vallon, O., Wollman, F. A., Recouvreur, M., \& Bennoun, P. (1986). Studies on the Cytochrome B6/F Complex .2. Localization of the Complex in the Thylakoid Membranes from Spinach and Chlamydomonas-Reinhardtii by Immunocytochemistry and Freeze-Fracture Analysis of B6/F Mutants. Biochimica et Biophysica Acta, 851(2), 239-248.

Ordon, J., Bressan, M., Kretschmer, C., Dall'Osto, L., Marillonnet, S., Bassi, R., \& Stuttmann, J. (2020). Optimized Cas9 expression systems for highly efficient Arabidopsis genome editing facilitate isolation of complex alleles in a single generation. Functional and Integrative Genomics, 20(1), 151-162. https://doi.org/10.1007/s10142-019-00665-4

Ordon, J., Gantner, J., Kemna, J., Schwalgun, L., Reschke, M., Streubel, J., Boch, J., \& Stuttmann, J. (2017). Generation of chromosomal deletions in dicotyledonous plants employing a user-friendly genome editing toolkit. Plant Journal, 89(1), 155-168. https://doi.org/10.1111/tpj.13319

Paolillo, D. J. J., \& Reighard, J. A. (2011). ON THE RELATIONSHIP BETWEEN MATURE STRUCTURE AND ONTOGENY IN THE GRANA OF CHLOROPLASTS. Https://Doi.Org/10.1139/B67-083, 45(6), 773-782. 
https://doi.org/10.1139/B67-083

Pietrzykowska, M., Suorsa, M., Semchonok, D. A., Tikkanen, M., Boekema, E. J., Aro, E. M., \& Jansson, S. (2014). The light-harvesting chlorophyll a/b binding proteins Lhcb1 and Lhcb2 play complementary roles during state transitions in Arabidopsis. Plant Cell, 26(9), 3646-3660. https://doi.org/10.1105/tpc.114.127373

Pribil, M., Labs, M., \& Leister, D. (2014). Structure and dynamics of thylakoids in land plants. In Journal of Experimental Botany (Vol. 65, Issue 8, pp. 1955-1972). J Exp Bot. https://doi.org/10.1093/jxb/eru090 Rappaport, F., Béal, D., Joliot, A., \& Joliot, P. (2007). On the advantages of using green light to study fluorescence yield changes in leaves. 1767, 56-65. https://doi.org/10.1016/j.bbabio.2006.10.002

Rhiel, E., \& Mörschel, E. (1993). The atypical chlorophyll a/b/c light-harvesting complex of Mantoniella squamata: molecular cloning and sequence analysis. Molecular and General Genetics MGG 1993 240:3, 240(3), 403-413. https://doi.org/10.1007/BF00280392

Schägger, H., \& von Jagow, G. (1987). Tricine-sodium dodecyl sulfate-polyacrylamide gel electrophoresis for the separation of proteins in the range from 1 to $100 \mathrm{kDa}$. Anal.Biochem., 166(2), 368-379. https://doi.org/10.1016/0003-2697(87)90587-2

Schiphorst, C., Achterberg, L., Go, R., Koehorst, R., Bassi, R., Amerongen, H. Van, Osto, L. D., Wientjes, E., \& Biotecnologie, D. (2021). The role of light-harvesting complex I in excitation energy transfer from LHCII to photosystem I in Arabidopsis. 1-12.

Schiphorst, C., \& Bassi, R. (2020). Chlorophyll-Xanthophyll Antenna Complexes: In Between Light Harvesting and Energy Dissipation. 27-55. https://doi.org/10.1007/978-3-030-33397-3_3

Schneider, C. A., Rasband, W. S., \& Eliceiri, K. W. (2012). NIH Image to ImageJ: 25 years of image analysis. https://doi.org/10.1038/nmeth.2089

Simpson, D. J. (1982). Freeze-fracture studies on barley plastid membranes V.viridis-n 34, a photosystem I mutant. Carlsberg Research Communications 1982 47:4, 47(4), 215-225. https://doi.org/10.1007/BF02907873

Simpson, D. J., \& Robinson, S. P. (1984). Freeze-Fracture Ultrastructure of Thylakoid Membranes in Chloroplasts from Manganese-Deficient Plants. Plant Physiology, 74(3), 735-741. https://doi.org/10.1104/PP.74.3.735

Simpson, D. J., Vallon, O., \& von Wettstein, D. (1989). Freeze-fracture studies on barley plastid membranes: VIII. In viridis-115, a mutant completely lacking Photosystem II, oxygen evolution enhancer 1 (OEE1) and the $\alpha$-subunit of cytochrome b-559 accumulate in appressed thylakoids. Biochimica et Biophysica Acta (BBA) - Bioenergetics, 975(1), 164-174. https://doi.org/10.1016/S0005-2728(89)80215-4

Slavov, C., Reus, M., \& Holzwarth, A. R. (2013). Two Different Mechanisms Cooperate In The DesiccationInduced Excited State Quenching In Parmelia Lichen. Journal of Physical Chemistry B, 117(38), 1132611336. https://doi.org/10.1021/JP402881F 
Standfuss, R., van Scheltinga, A. C. T., Lamborghini, M., \& Kuhlbrandt, W. (2005). Mechanisms of photoprotection and nonphotochemical quenching in pea light-harvesting complex at 2.5A resolution. Embo Journal, 24(5), 919-928.

Towbin, H., Staehelin, T., \& Gordon, J. (1979). Electrophoretic transfer of proteins from polyacrylamide gels to nitrocellulose sheets: Procedure and some applications. Proceedings of the National Academy of Sciences, 76(9), 4350-4354. https://doi.org/10.1073/pnas.76.9.4350

Trissl, H. W., \& Wilhelm, C. (1993). Why do thylakoid membranes from higher plants form grana stacks? Trends in Biochemical Sciences, 18(11), 415-419. https://doi.org/10.1016/0968-0004(93)90136-B

Vallon, O., Bulte, L., Dainese, P., Olive, J., Bassi, R., \& Wollman, F. A. (1991). Lateral redistribution of cytochrome $b 6 / f$ complexes along thylakoid membranes upon state transitions. Proc.NatI.Acad.Sci.U.S.A, 88(0027-8424 SB-IM), 8262-8266.

Wietrzynski, W., Schaffer, M., Tegunov, D., Albert, S., Kanazawa, A., Plitzko, J. M., Baumeister, W., \& Engel, B. D. (2020). Charting the native architecture of Chlamydomonas thylakoid membranes with singlemolecule precision. ELife, 9, 1-18. https://doi.org/10.7554/eLife.53740

Wilhelm, C., Krämer, P., \& Lenartz-Weiler, I. (1989). The energy distribution between the photosystems and light-induced changes in the stoichiometry of system I and II reaction centers in the chlorophyll bcontaining alga Mantoniella squamata (Prasinophyceae). Photosynthesis Research 1989 20:3, 20(3), 221-233. https://doi.org/10.1007/BF00034066

Zhang, X., Henriques, R., Lin, S.-S., Niu, Q.-W., Chua, N.-H., Niu, W.-W., Chua, N.-H., Niu, Q.-W., \& Chua, N.H. H. N.-H. (2006). Agrobacterium-mediated transformation of Arabidopsis thaliana using the floral dip method. Nature Protocols, 1(2), 641-646. https://doi.org/10.1038/nprot.2006.97 
Figures
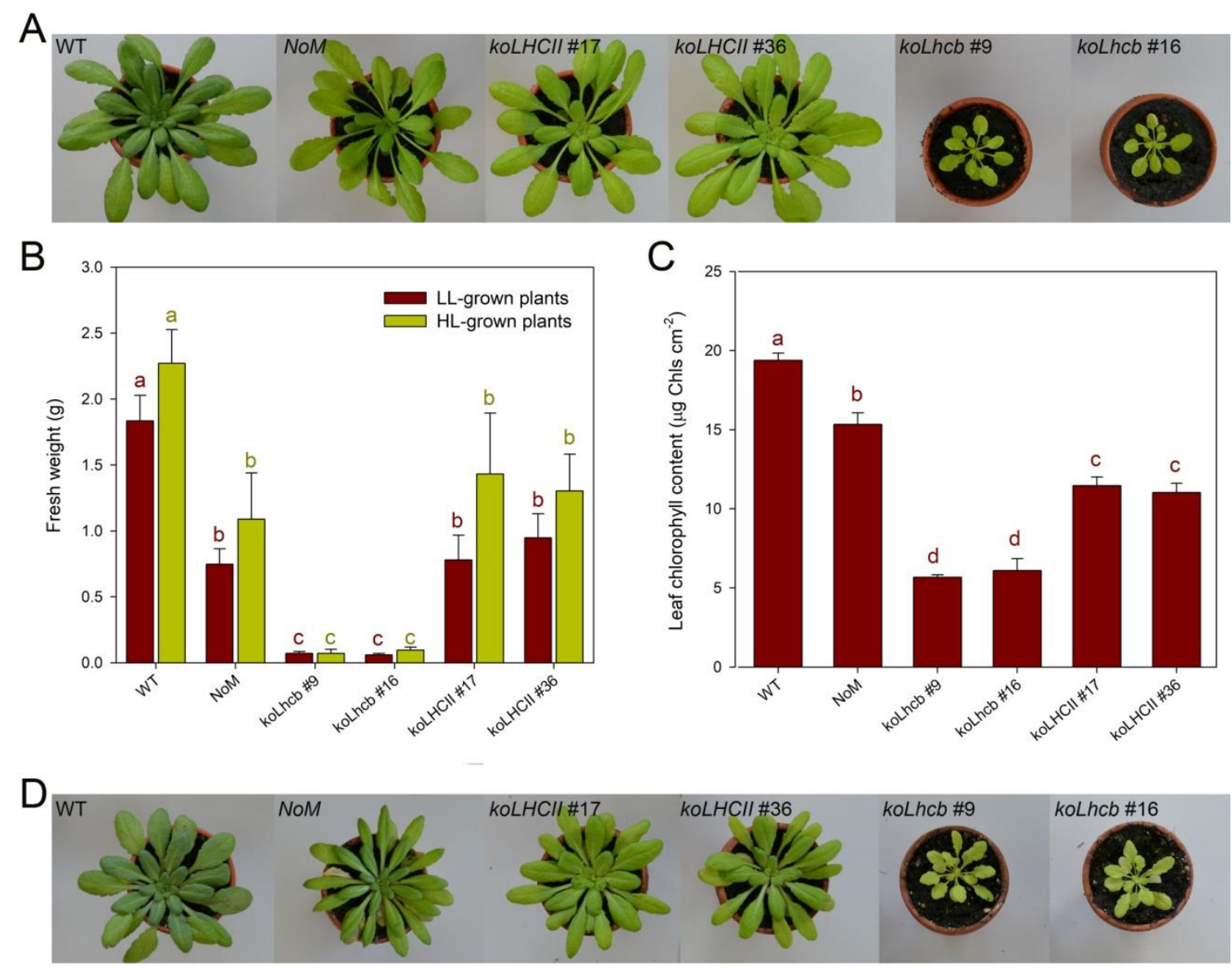

Figure 1. Phenotype of wild type and mutant plants. (A) Plants were grown for 6 weeks at $150 \mu$ mol photons $\mathrm{m}^{-2} \mathrm{~s}^{-1}, 23^{\circ} \mathrm{C}, 8 / 16 \mathrm{~h}$ light/dark (LL). (B)

(B) The fresh weight of all. Values are expressed as mean $\pm S D, n=10$. Leaf Chl content. koLhcb lines retained only $25 \%$ of $\mathrm{Chl}$ per area, while NoM and koLHCIl retained $75 \%$ and $50 \%$, respectively. Values are expressed as mean $\pm S D, n=4$. (D) Plant growth for 6 weeks at $350 \mu$ mol photons $\mathrm{m}^{-2} \mathrm{~s}^{-1}, 23^{\circ} \mathrm{C}, 8 / 16 \mathrm{~h}$ light/dark (HL). NoM and koLHCll showed similar growth while koLhcb lines were much smaller, alike in CTRL light (panel B). Leaf Chl content relative to the wild type remained essentially the same in LL vs HL (panel C). Values that are significantly different from the corresponding wild type (ANOVA followed by Tukey's post-hoc test at a significance level of $P<0.05$ ) are marked with different letters. 
A

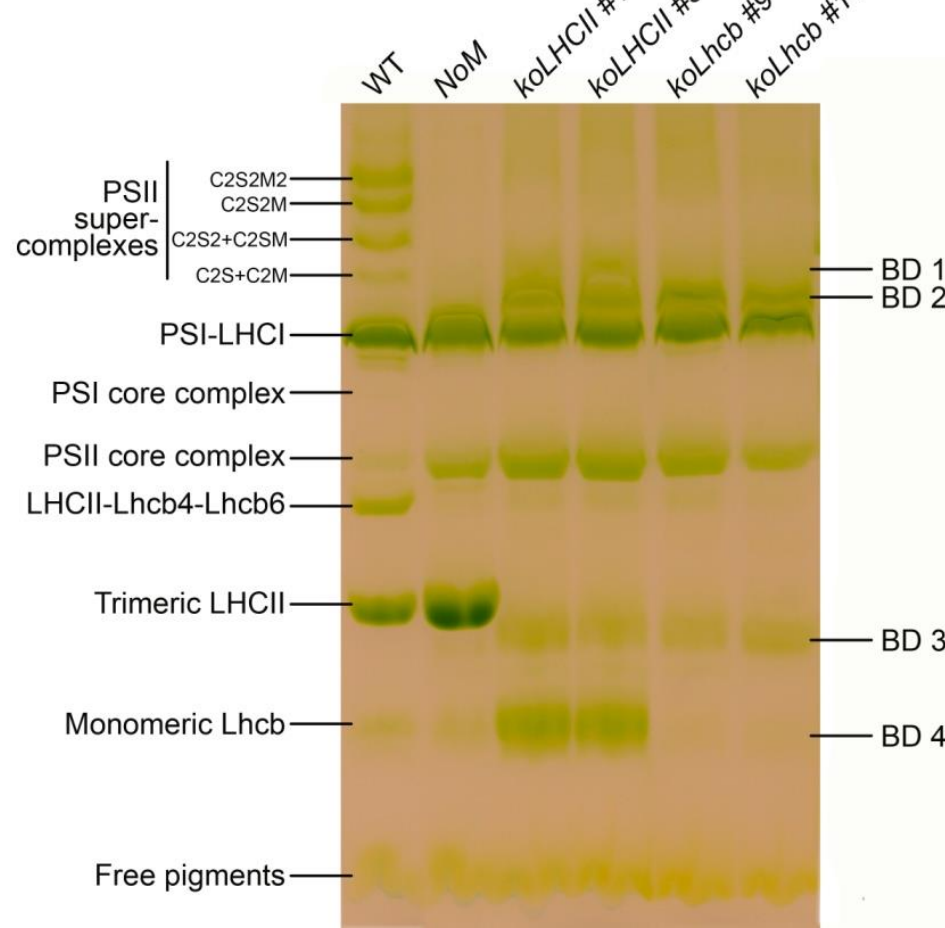

$\mathrm{B}$

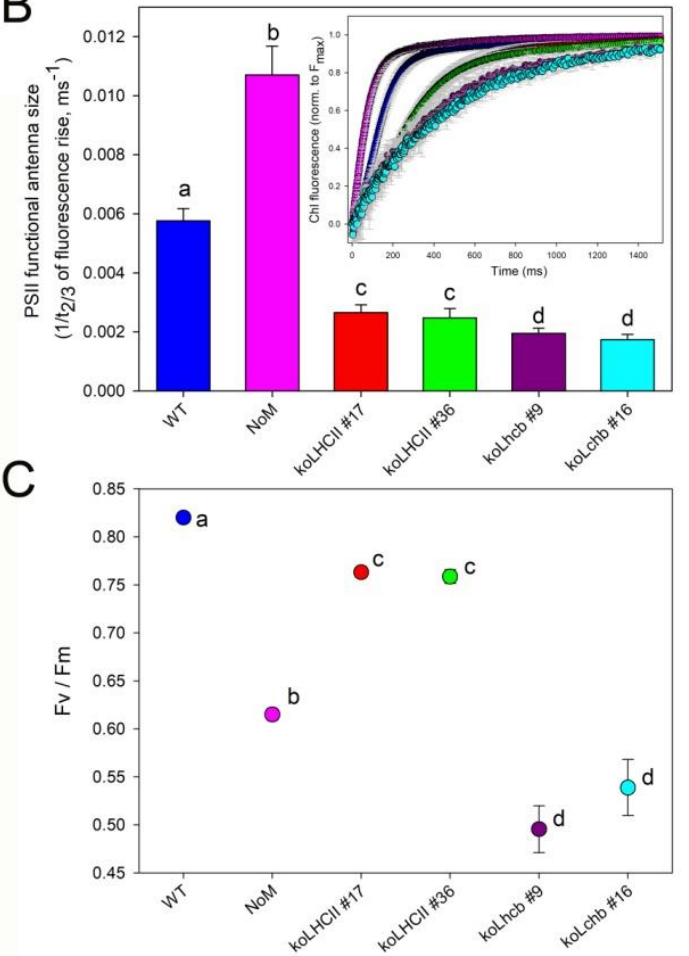

Figure 2. Biochemical and functional characterization of the photosynthetic apparatus of wild type and

mutant plants. (A) Non-denaturing Deriphat-PAGE of thylakoids upon solubilization with $0.8 \% \alpha-D M$, revealing pigment-protein complexes of wild type, NoM, koLHCII and koLhcb lines. Thylakoid proteins corresponding 20-35 $\mu \mathrm{g}$ of Chls were loaded in each lane. The composition of major bands is indicated based on previous reports, while that of bands BD1-BD4 was determined from absorption spectra and SDS-PAGE (Supplementary Figure S2). (B) PSII functional antenna size of wild type and mutants, measured at RT on leaves vacuum-infiltrated with $50 \mu \mathrm{M}$ DCMU. The reciprocal of time corresponding to two-thirds of the fluorescence rise $\left(t_{2 / 3^{-1}}\right)$ was taken as a measure of the PSII functional antenna size. Plants were dark-adapted for 30 min before measurements. Data are expressed as mean \pm SD $(n=9)$. Values marked with different letters are significantly different from each other (ANOVA followed by Tukey's post-hoc test at a significance level of $\mathrm{P}<0.05)$. (C) PSII maximal quantum yield $\left(\mathrm{F}_{\mathrm{v}} / \mathrm{F}_{\mathrm{m}}\right)$ of wild type, NoM, koLHCII and koLhcb lines, measured on dark adapted leaves. Symbols and error bars show means $\pm S D(n=4)$. Values that are significantly different (ANOVA followed by Tukey's post-hoc test at a significance level of $P<0.05$ ) are marked with different letters. 

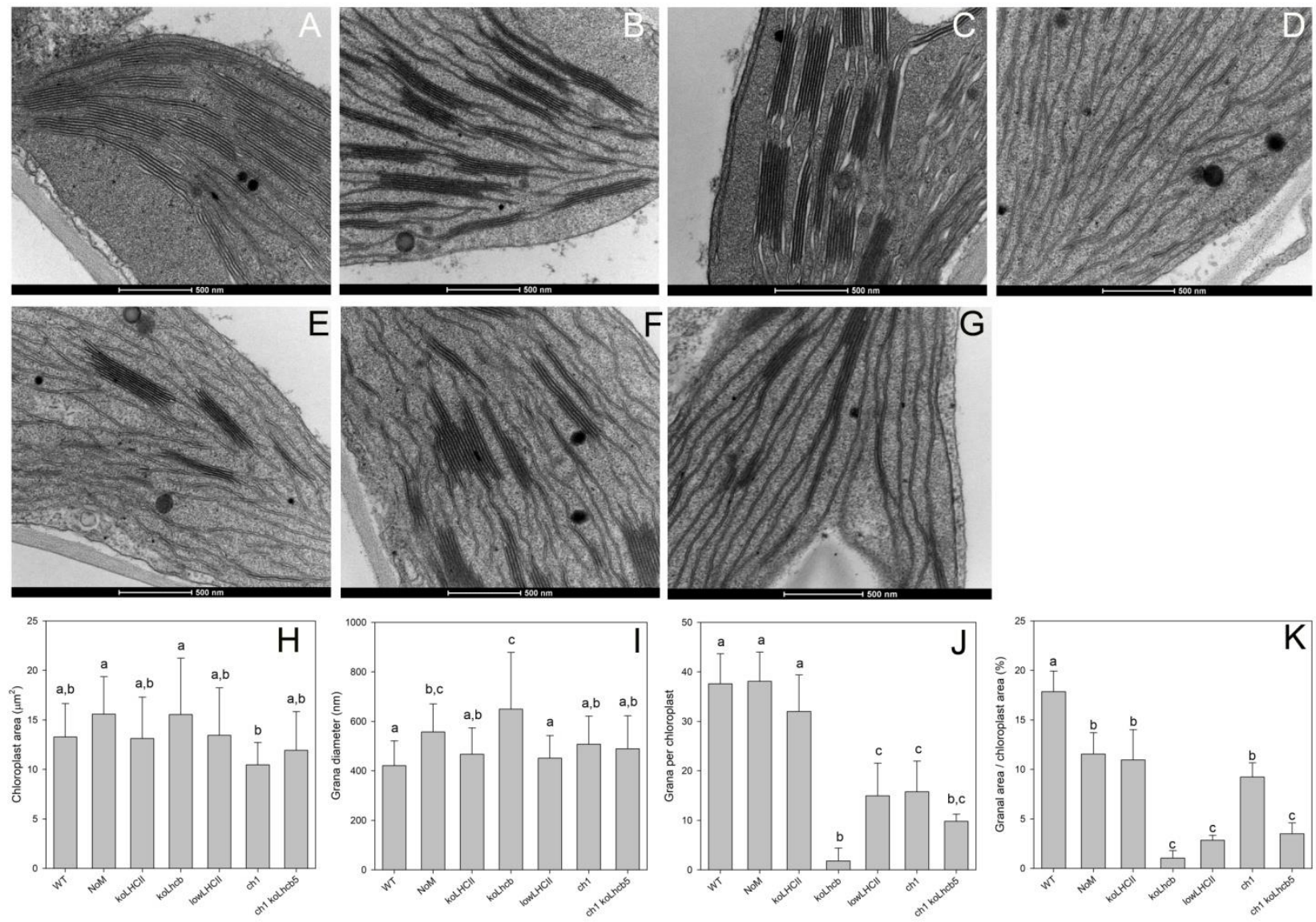

Figure 3. Transmission electron micrographs of plastids from leaf mesophyll cells of wild type and mutant

lines. (A-D) Plants grown in short-day conditions were dark-adapted for 2 hours before harvesting leaves, then samples were fixed, embedded, and observed in thin sections at different levels of magnification. Wild type (A), NoM (B) and KoLHCII (C) showed a characteristic organization of stroma lamellae interconnecting grana, while the chloroplasts of koLhcb (D) lacked grana. (E-G) Micrograph of lowLHCII (E), ch1 (F) and ch1 koLhcb5 (G) chloroplasts. (H-K) Statistical analysis of the extent of the thylakoid stacking in the wild type, LHC KO lines and Chl $b$-less mutants ch1 and ch1 koLhcb5. Histograms report: (H) chloroplast area ( $\mathrm{n} \geq 12)$; (I) grana diameter [n = 22 (wild type), 27 (NoM), 26 (koLHCll, Lhcb2-only), 7 (koLhcb), 25 (ch1 lines); (J) grana per chloroplast $(n \geq 8)$; (K) granal area vs. chloroplast area $(n \geq 5)$. Data are shown as mean \pm SD. Values that are significantly different (ANOVA followed by Tukey's post hoc test at a significance level of $P<0.05$ ) are marked with different letters. 

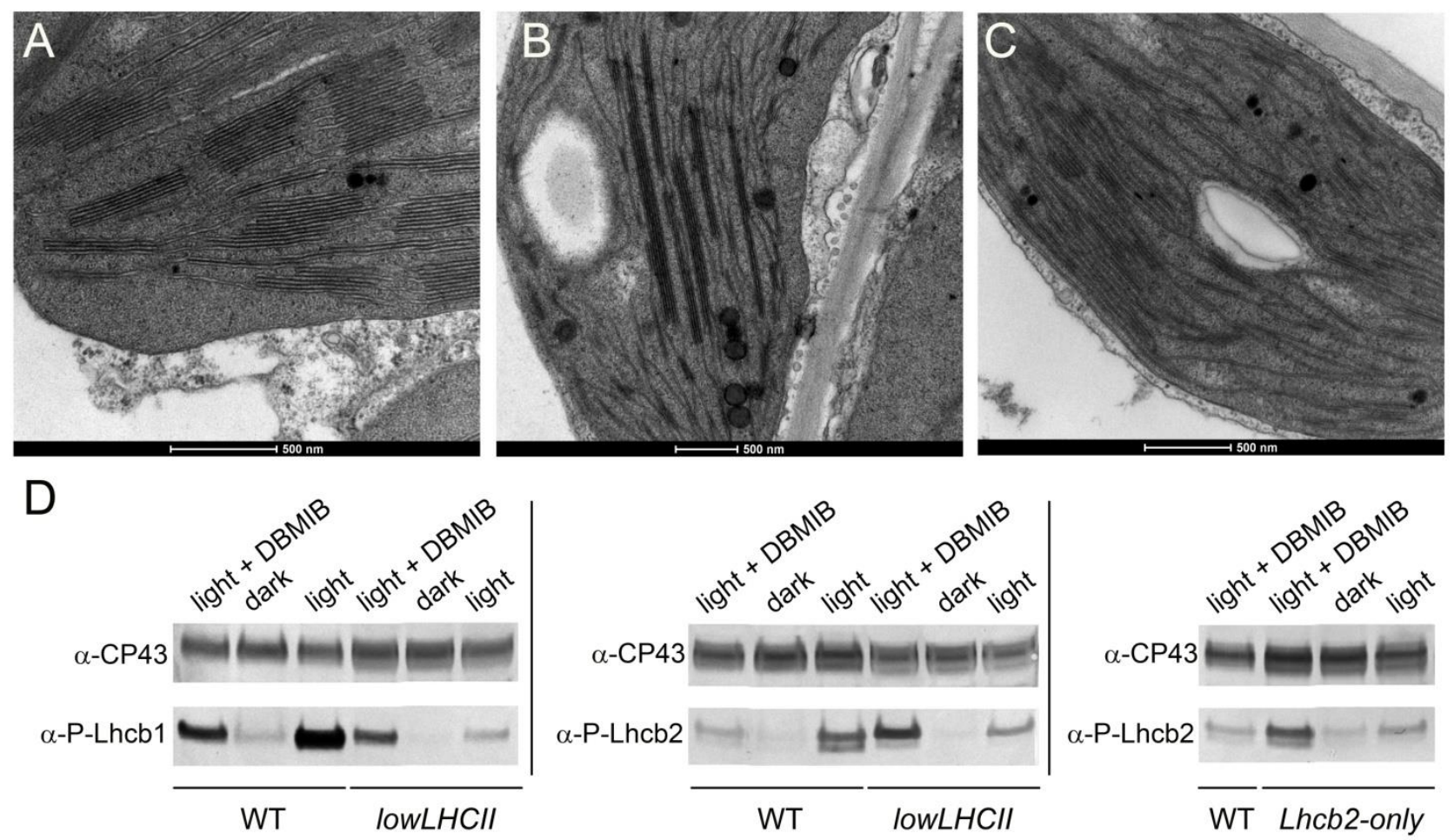

E
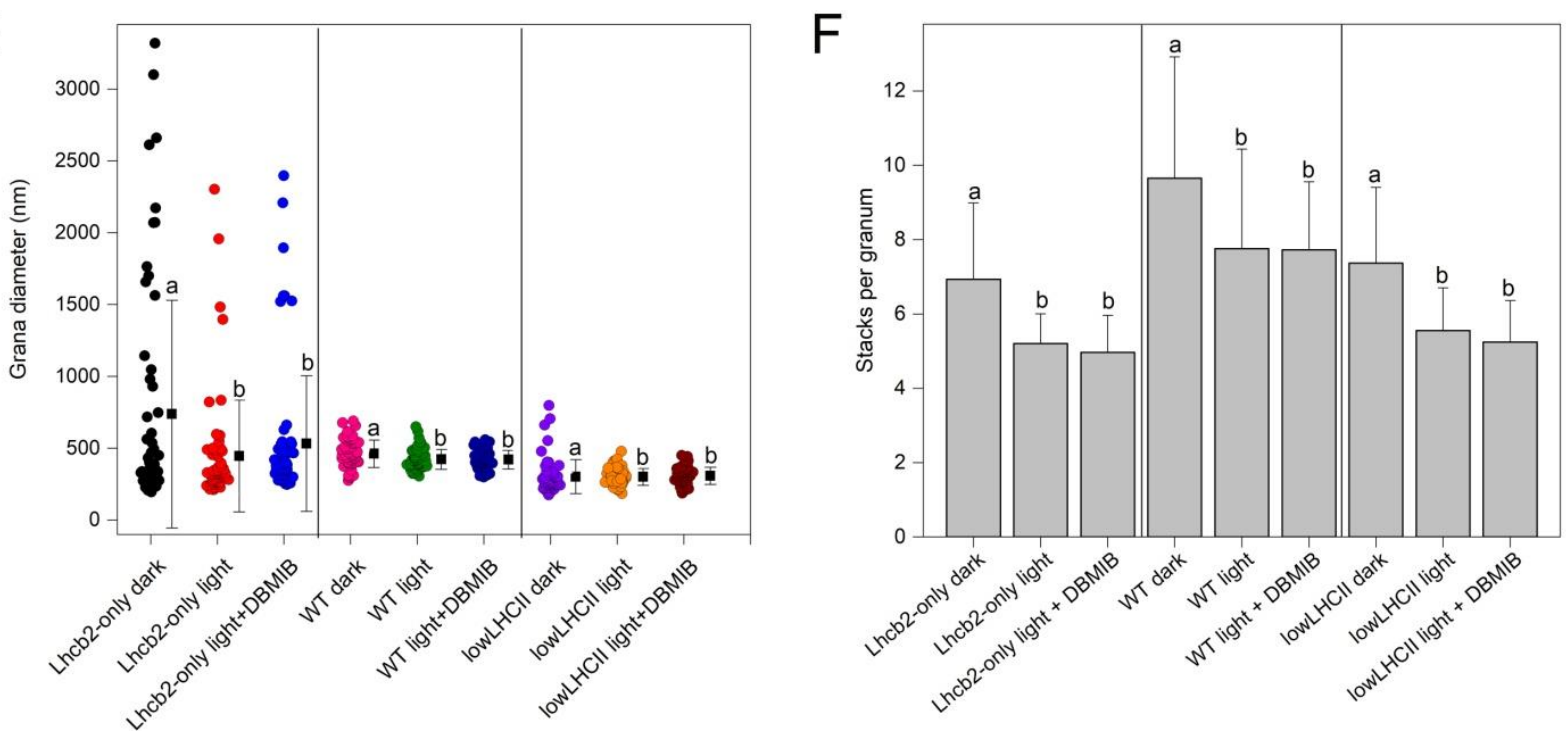

Figure 4. Changes in chloroplast ultrastructure of state 1- and state 2-adapted leaves. (A-C) Leaves from

wild type (A), Lhcb2-only (B) and lowLHCII (C) plants were subjected to 2 hours of PSII light ( $200 \mu$ mol photons $\mathrm{m}^{-2} \mathrm{~s}^{-1}$ ) to promote LHCII phosphorylation and transition to state 2 . Reference samples included leaves either dark-adapted for 1 hours or exposed to PSII light upon vacuum-infiltration with $100 \mu$ M DBMIB to maximize $P Q$ reduction thus LHCII phosphorylation. Leaf discs were then fixed, embedded, and observed in thin sections. (D) Leaf discs from the same treatments were snap frozen, then the phosphorylation level of Lhcb1/Lhcb2 was quantified by immunotitration, using $\alpha$-lhcb1-P and $\alpha-\operatorname{lhcb} 2-\mathrm{P}$ primary antibodies. Proteins corresponding to $0.8 \mu \mathrm{g}$ of Chls (wild type sample) or $2.4 \mu \mathrm{g}$ of Chls (mutant samples) were loaded for each sample. All samples were loaded on the same SDS-PAGE slab gel. (E) Statistical analysis of differences in grana diameter, in state 1 and state 2 [ $=60$ (Lhcb2-only), 55 (wild type), 58 (lowLHCII)]. (F) Statistical analysis of 
the average number of layers in grana stacks, in state 1 and state $2(n=30)$. Data $(E, F)$ are expressed as mean \pm SD. Values that are significantly different (ANOVA followed by Tukey's post-hoc test at a significance level of $\mathrm{P}<0.05)$ are marked with different letters.

770
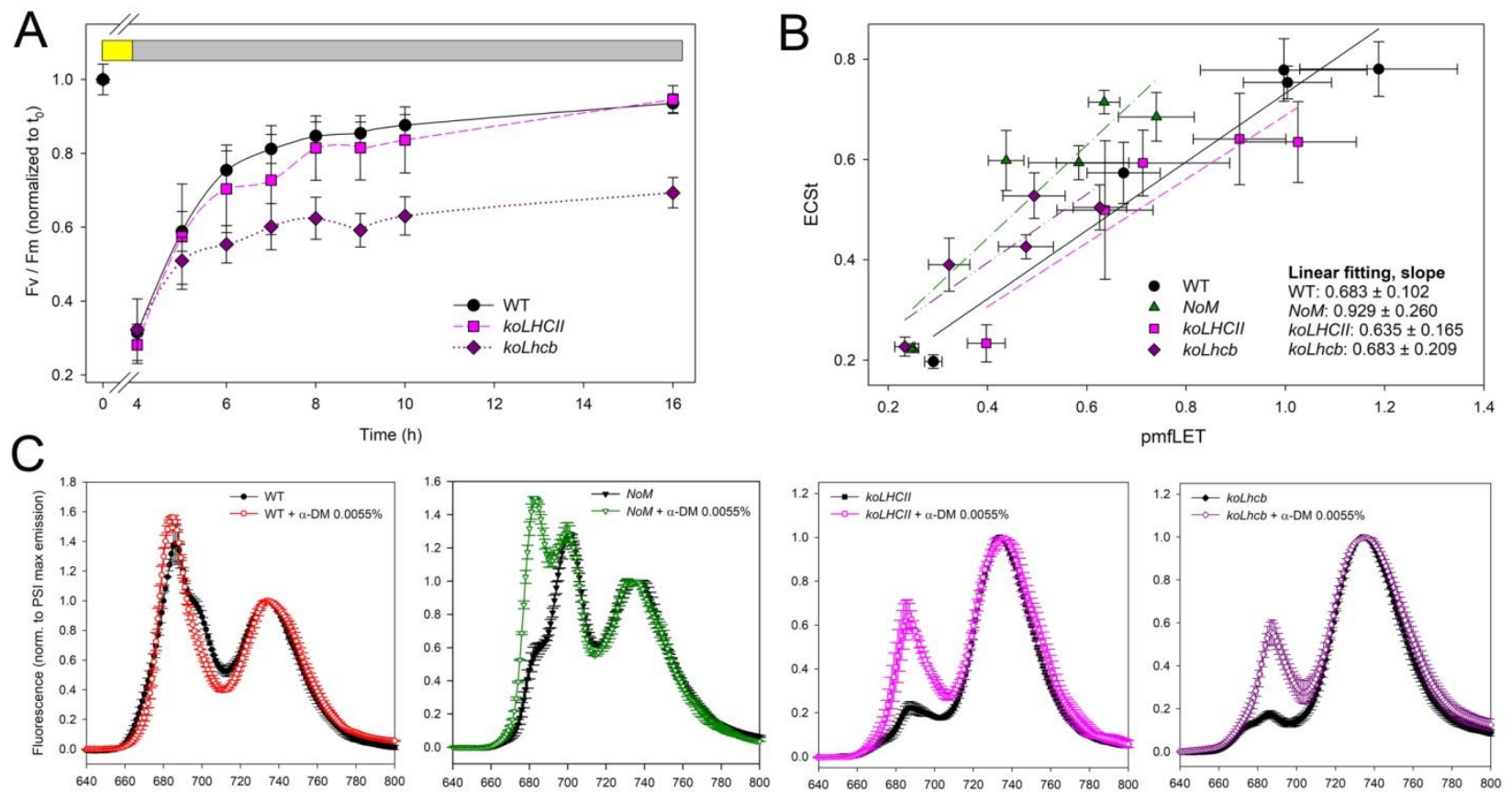

Figure 5. Biophysical characterization of the mechanisms regulating energy transduction reactions in

thylakoids. (A) PSII repair efficiency. Detached leaves were exposed to EL for 3 hours (wild type, $1100 \mu \mathrm{mol}$ photons $\mathrm{m}^{-2} \mathrm{~s}^{-1}$; koLHCII, $900 \mu \mathrm{mol}$ photons $\mathrm{m}^{-2} \mathrm{~s}^{-1}$; koLhcb, $750 \mu \mathrm{mol}$ photons $\mathrm{m}^{-2} \mathrm{~s}^{-1}$ ) at $4^{\circ} \mathrm{C}$, to reduce PSII maximal quantum yield $\left(F_{v} / F_{m}\right)$ to about $30 \%$ of the initial value. Recovery of $F_{v} / F_{m}$ was performed at $15 \mu$ mol photons $\mathrm{m}^{-2} \mathrm{~s}^{-1}, 24^{\circ} \mathrm{C}$. koLhcb line showed a slower PSII repair kinetic compared to both wild type and koLHCII. Values are expressed as mean $\pm S D, n=5$. (B) Relationship between pmfLET and ECSt in wild type and mutant lines upon steady state illumination. All genotypes showed similar amplitude of total ECS as a function of LET, thus suggesting a similar amplitude of CEF. Values are expressed as mean $\pm S D, n=4$. (C) $77 \mathrm{~K}$ fluorescence emission spectra were recorded on thylakoids from wild type, NoM, koLHCIl and koLhcb plants, before and after treatment with $0.0055 \% \alpha$-DM, severing weak interactions between Chl-binding complexes without solubilizing the membranes. Upon treatment, wild type and NoM showed an increased emission by PSII, ascribed to LHCII population disconnected from PSII RC; koLHCII and koLhcb showed a far higher emission by PSII upon treatment, suggesting the presence of PSII-to-PSI spill-over in these lines. Spectra were normalized to the maximal emission of PSI-LHCl at $733 \mathrm{~nm}$. $\lambda_{\mathrm{exc}}=440 \mathrm{~nm}$. Symbols and error bars show means $\pm \mathrm{SD}, \mathrm{n}=$ 
Table 1. Pigment content and fluorescence induction parameters determined for leaves of Arabidopsis WT and mutant lines. At least five different plants were tested for each line. Chl/Car, molar ratio between chlorophylls $(a+b)$ and carotenoids. Fresh weight refers to growth after 6 weeks under control conditions. Data are expressed as mean $\pm S D, n=6$ biologically independent leaves. Values marked with different letters are significantly different from each other within the column (ANOVA, followed by Tukey's post-hoc test at a significance level of $P<0.05)$. Experiments were repeated independently twice, with similar results.

\begin{tabular}{|l|l|l|l|l|}
\hline & Chl a / b & Chl / Car & $\mu$ Chl cm & F \\
\hline WT & $3.51 \pm 0.09^{\mathrm{a}}$ & $3.69 \pm 0.21^{\mathrm{a}}$ & $19.4 \pm 0.5^{\mathrm{a}}$ & $0.82 \pm 0.01^{\mathrm{a}}$ \\
\hline NoM & $3.28 \pm 0.05^{\mathrm{a}}$ & $3.45 \pm 0.09^{\mathrm{a}, \mathrm{b}}$ & $15.3 \pm 0.74^{\mathrm{b}}$ & $0.61 \pm 0.01^{\mathrm{b}}$ \\
\hline koLHCII \#17 & $5.23 \pm 0.11^{\mathrm{b}}$ & $3.37 \pm 0.06^{\mathrm{b}}$ & $11.46 \pm 0.55^{\mathrm{c}}$ & $0.76 \pm 0.01^{\mathrm{c}}$ \\
\hline koLHCII \#36 & $5.15 \pm 0.10^{\mathrm{b}}$ & $3.34 \pm 0.02^{\mathrm{b}}$ & $11.03 \pm 0.58^{\mathrm{c}}$ & $0.76 \pm 0.01^{\mathrm{c}}$ \\
\hline koLhcb \#9 & $6.28 \pm 0.15^{\mathrm{c}}$ & $3.12 \pm 0.05^{\mathrm{c}}$ & $5.68 \pm 0.15^{\mathrm{d}}$ & $0.50 \pm 0.02^{\mathrm{e}}$ \\
\hline koLhcb \#16 & $6.14 \pm 0.22^{\mathrm{c}}$ & $3.09 \pm 0.08^{\mathrm{c}}$ & $6.10 \pm 0.76^{\mathrm{d}}$ & $0.54 \pm 0.03^{\mathrm{e}}$ \\
\hline ch1 & - & $2.77 \pm 0.02^{\mathrm{c}}$ & $6.55 \pm 0.54^{\mathrm{d}}$ & $0.78 \pm 0.01^{\mathrm{c}}$ \\
\hline ch1 koLhcb5 & - & $2.57 \pm 0.02^{\mathrm{c}}$ & $4.50 \pm 0.23^{\mathrm{e}}$ & $0.67 \pm 0.01^{\mathrm{d}}$ \\
\hline lowLHCII \#14 & $4.01 \pm 0.22^{\mathrm{d}}$ & $3.01 \pm 0.06^{\mathrm{b}}$ & $7.24 \pm 0.87^{\mathrm{c}}$ & $0.52 \pm 0.05^{\mathrm{e}}$ \\
\hline lowLHCII \#32 & $4.71 \pm 0.39^{\mathrm{b}, \mathrm{d}}$ & $2.98 \pm 0.03^{\mathrm{b}}$ & $7.58 \pm 1.01^{\mathrm{c}}$ & $0.55 \pm 0.05^{\mathrm{e}}$ \\
\hline Lhcb2-only & $3.96 \pm 0.16^{\mathrm{e}}$ & $3.18 \pm 0.11^{\mathrm{b}}$ & $9.77 \pm 1.82^{\mathrm{c}}$ & $0.51 \pm 0.02^{\mathrm{e}}$ \\
\hline
\end{tabular}


bioRxiv preprint doi: $h$ ttps://doi.org/10.1101/2021.12.31.474624: this version posted January 1 . 2022. The copvriaht holder for this preprint (which was not certified by peer review) is the author/funder, who has granted bioRxiv a license to display the preprint in perpetuity. It is made available under aCC-BY-NC-ND 4.0 International license. 